\title{
Assessment of thermodynamic models for the design, analysis and optimisation of gas liquefaction systems
}

Nguyen, Tuong-Van; Elmegaard, Brian

Published in:

Applied Energy

Link to article, DOI:

10.1016/j.apenergy.2016.08.174

Publication date:

2016

Document Version

Peer reviewed version

Link back to DTU Orbit

Citation (APA):

Nguyen, T-V., \& Elmegaard, B. (2016). Assessment of thermodynamic models for the design, analysis and optimisation of gas liquefaction systems. Applied Energy, 183, 43-60.

https://doi.org/10.1016/j.apenergy.2016.08.174

\section{General rights}

Copyright and moral rights for the publications made accessible in the public portal are retained by the authors and/or other copyright owners and it is a condition of accessing publications that users recognise and abide by the legal requirements associated with these rights.

- Users may download and print one copy of any publication from the public portal for the purpose of private study or research.

- You may not further distribute the material or use it for any profit-making activity or commercial gain

- You may freely distribute the URL identifying the publication in the public portal

If you believe that this document breaches copyright please contact us providing details, and we will remove access to the work immediately and investigate your claim. 


\title{
Assessment of thermodynamic models for the design, analysis and optimisation of gas liquefaction systems
}

\author{
Tuong-Van Nguyen ${ }^{\mathrm{a}, *}$, Brian Elmegaard ${ }^{\mathrm{a}}$ \\ ${ }^{a}$ Section of Thermal Energy, Department of Mechanical Engineering, Technical University of Denmark, \\ Building 403, Nils Koppels Allé, 2800 Kongens Lyngby, Denmark
}

\begin{abstract}
Natural gas liquefaction systems are based on refrigeration cycles - they consist of the same operations such as heat exchange, compression and expansion, but they have different layouts, components and working fluids. The design of these systems requires a preliminary simulation and evaluation of their performance. However, the thermodynamic models used for this purpose are characterized by different mathematical formulations, ranges of application and levels of accuracy. This may lead to inconsistent results when estimating hydrocarbon properties and assessing the efficiency of a given process. This paper presents a thorough comparison of six equations of state widely used in the academia and industry, including the GERG-2008 model, which has recently been adopted as an ISO standard for natural gases. These models are used to (i) estimate the thermophysical properties of a Danish natural gas, (ii) simulate, and (iii) optimize liquefaction systems. Three case studies are considered: a cascade layout with three pure refrigerants, a single mixed-refrigerant unit, and a turbine-based configuration. Significant deviations are found between all property models, and in all case studies. The main discrepancies are related to the prediction of the energy flows (up to $7 \%$ ) and to the heat exchanger conductances (up to 11\%), and they are not systematic errors. The results illustrate the superiority of using the GERG-2008 model for designing gas processes in real applications, with the aim of reducing their energy use. They demonstrate as well that particular caution should be exercised when extrapolating the results of the conventional thermodynamic models to the actual conception of the gas liquefaction chain.
\end{abstract}

Keywords: Gas liquefaction, thermodynamic model, equation of state, efficiency, optimisation

\section{Introduction}

\subsection{Background}

Production of liquefied natural gas (LNG) is an energy-intensive process that represents about $4 \%$ of the gas energy content. Minimising the energy use of this system has received increasing interest in the design procedure [1,2]. Liquefied natural gas is natural gas that has been converted to liquid form, while compressed natural gas $(\mathrm{CNG})$ is natural gas in a gaseous state and at high pressure. At typical storage conditions $\left(-160{ }^{\circ} \mathrm{C}\right.$ for $\mathrm{LNG}$ and 250 bar for CNG), the energy density of LNG is about $22 \mathrm{MJ}$ per litre, which is about 2.4 times greater than that of CNG [3]. The higher heating value of LNG and CNG ranges between 52 and $54 \mathrm{MJ} / \mathrm{kg}$, which is about $3 \%$ lower than that of pure methane, but higher than those of crude oil, coal and biomass. These properties make LNG suitable for storage and long-distance transportation, and its use in marine applications seems promising in the future, because of the new limits on nitrogen and sulphur oxides emissions established by the International Marine Organization (IMO) within the Annex VI of the MARPOL treaty [4].

\footnotetext{
*Principal corresponding author. Tel.: +45 4525 4129

Email address: tungu@mek.dtu.dk (Tuong-Van Nguyen)
} 
The liquefaction process consists of the following steps. Natural gas is received at ambient temperature and above atmospheric pressure. It is then precooled, condensed and subcooled down to $-160{ }^{\circ} \mathrm{C}$, and is finally flashed off to the storage conditions. Heat removal in these cryogenic conditions is ensured by refrigeration, which implies the need for input power and heat rejection to the ambient conditions. Natural gas is a mixture containing light- (methane and ethane), medium- (propane and butane) and heavy-weight (pentane and others) hydrocarbons, together with impurities (carbon dioxide, water and nitrogen), which are removed upstream. This mixture is zeotropic: at a constant pressure, it condenses along a temperature glide and the compositions of the two phases in the vapour-liquid region are never the same.

\subsection{Literature review}

Several refrigeration processes for gas liquefaction have been developed over the last half-century. The scientific literature shows a large number of studies on the modelling, analysis and optimisation of gas liquefaction systems. Several handbooks, such as the ones of McDermott and Ranney[5] and of Mokhatab and Poe[6], as well as the papers of Lim et al.[7] and of Chang[8], present the cycles that have attracted most interest up-to-now. As discussed in Venkatarathnam and Timmerhaus[9], they can be subdivided into the cascade, mixed refrigerant and expander-based processes. The selection, in practice, of a particular process depends on considerations such as the system performance (compression duty), cost (equipment), size (heat exchangers), simplicity (item inventory) and safety (working fluid) [10,11]. It is therefore not possible to propose a suitable process for all applications, as different fields of application have different requirements. For example, mixed-refrigerant and expander-based processes may be preferred for smallscale applications [12] because of their lower equipment inventory, while cascade, dual [13] and propaneprecooled $[14,15]$ mixed-refrigerant systems are preferred for systems where high efficiency is the prime criterion. Mixed-refrigerant processes attract a lot of attention because of their high efficiency and their use in many industrial applications, but the high number of degrees of freedom when designing such systems results in a complex problem. Mortazavi et al.[16] suggest the use of alternative expansion techniques to enhance the performance of the C3MR process. Li et al.[17] present an optimisation methodology for optimising the design parameters of gas liquefaction processes applicable to hydrogen and methane. Khan et al.[18] propose a novel method for selecting the most appropriate refrigerant composition, which is applied to a single and propane precooled mixed system. In the same line, Xu et al.[19] suggest a correlation between the refrigerant composition and ambient conditions to design more efficient PRICO processes.

Several papers present a performance comparison of gas liquefaction processes. Remeljej and Hoadley[12] assess four LNG processes for small-scale production, suggesting that expander-based and open processes are preferable for offshore applications. Cao et al.[20] optimise two simple liquefaction configurations of the mixed refrigerant and expander-based categories. Lee et al.[21] propose and compare the integration of different single mixed-refrigerant processes for floating LNG plants. Vatani et al.[22] analyse five different systems using energy and exergy-based methods.

The vast majority of these papers, if not all, considers only one thermodynamic model in the simulation and optimisation procedure of the LNG system. The annotated bibliography of Austbø et al.[23] shows that the equation of state (EOS) of Peng-Robinson (PR) [24] is by far the most widely used thermodynamic models in academia and industry, as also indicated by Chen and Mathias[25]. The second most popular is the Redlich-Kwong [26] EOS with Soave modifications (SRK) [27]. A few use the Reference Fluid Thermodynamic and Transport Properties (REFPROP) database developed by the National Institute of Standards and Technology (NIST) [28]. It builds on the models developed by the Groupe Européen de Recherches Gazières [29], to which other hydrocarbons such as ethylene are added [30]. Even fewer consider equations of the virial family such as the Benedict-Webb-Rubin Benedict et al.[31,32] and the Lee-Kesler [33] with Plöcker adjustments [34] models. No archival studies on the design of LNG processes based on the 'Statistical Association Fluid Theory' (SAFT) [35,36], such as the models based on the perturbated chain (PC) theory, were published prior to 2013.

The accuracy of these models for deriving natural gas properties has been discussed in the last decades. Ting et al.[37] evaluate the ability of the PR and SAFT EOS to predict phase equilibrium for mixtures of $n$-alkanes. They conclude that the PR EOS is surprisingly accurate if the pure component parameters were appropriately regressed. The PC-SAFT EOS is recommended if no empirical data is available, but 
presents deficiencies near the critical region. Martinez and Hall[38] draw similar conclusions, claiming that cubic EOS have good predictive ability despite their simplicity. Nasrifar et al.[39] compare 15 cubic EOS for predicting natural gas dew points, and show that the Redlich-Kwong family is more accurate for lean gases, while the Patel-Teja category is more satisfying for rich ones. Aparicio-Martínez and Hall[40,41,42] demonstrate that SAFT equations based on the PC theory describe accurately the phase behaviour of binary mixtures commonly found in natural gases. Diamantonis et al.[43] present similar findings but also pinpoint that the PC-SAFT, PR and SRK EOS are of comparable accuracy if binary parameters are experimentally fitted. The works of Kunz et al.[29],Kunz and Wagner[44] show that the PR EOS is not satisfying enough for predicting methane properties, while the GERG model are in excellent agreement with experiments on natural gas mixtures. Dauber and Span[45] showed that this model returns results within the experimental uncertainties for different natural gas applications (liquefaction and reboiling), which makes this model a reference for predicting the thermophysical properties of gas mixtures. Melaaen and Owren[46] analyse how inaccuracies in the SRK model propagate using a probabilistic simulation method, but do not compare the influence of using different equations of state.

Few works investigate the relation between the accuracy of thermodynamic models and their influence on the design of liquefaction processes. Among them, Dauber and Span[45] focus on the most important processes of the LNG chain (liquefaction and transport), comparing the GERG-2008 model of Kunz and Wagner[44] to the conventional PR, SRK and LKP EOS. They discuss the uncertainties related to each thermodynamic model, taking a simplified subcooling process as example, and conclude that the LKP EOS presents the greatest deviation in the calculation of the heat flows. Yuan et al.[47] performs a similar comparison, focusing on the same models, and based on the use of the Aspen Plus software. The same conclusions are drawn. These two works consider the GERG model as a reference because of the small uncertainties for all volumetric and calorific properties, which are within the range of experimental measurements. This model is at present the most accurate one, and has been validated against real plant data of liquefaction plants, such as the Snøhvit one in Norway. At present, it is used by the Groupe Européen de Recherches Gazières, which includes large gas companies such as Enagás, Statoil and Gaz de France. It is now implemented in software components adhering to the CAPE-OPEN standard, embedded in multiple software such as Aspen PLUS and Aspen HYSYS, and is adopted as an ISO standard (ISO 20765-2 and ISO 20765-3) for natural gases.

\subsection{Objectives}

Most of the reviewed studies focus either (i) on the prediction of natural gas properties, without evaluating the influence of these uncertainties in process design, or (ii) on the design of liquefaction processes, without comparing different thermodynamic models. The aim is to address these gaps, by reviewing and using methods in chemical engineering and engineering thermodynamics. The novelty of the present paper is thus two-sided. On the one hand, a process belonging to each family of liquefaction systems is modelled, optimised and compared against the others in terms of energy use, efficiency and size. On the other hand, the thermodynamic property packages commonly used in academic and industrial research are compared against the new standards, in terms of property prediction and system design. Compared to the previous research in that field, this study (i) includes equations of state based on molecular modelling besides cubic, virial and fundamental ones, (ii) considers the impact of thermodynamic uncertainties on several types of liquefaction processes, and (iii) evaluates how those influence the plant sizing and optimisation.

The structure of the paper is as follows. Section 2 presents an overview of the different thermodynamic models and processes under study, along with the simulation and optimisation methods. Section 3 goes through the comparison of the different EOS with regards to the prediction of the natural gas properties, component sizing and system optimisations. Section 4 discusses the main findings and their significance in terms of industrial applications, while Section 5 concludes the present work and suggests possibilities for future work. 


\section{Methods}

The present work compares several equations of state, from the prediction of natural gas properties to the design of gas liquefaction systems. These thermodynamic models differ in their level of complexity, accuracy and level of use, and are, according to the literature [23], widely used in the academia and natural gas industry:

- cubic EOS: Peng-Robinson [24] and Redlich-Kwong with Soave modifications [26];

- virial EOS: Benedict-Webb-Rubin [31,32] with Starling modifications [48] and Lee-Kesler [33] with Plöcker adjustments [34];

- fundamental EOS based on either chemical modelling ('Statistical Association Fluid Theory' [35,36], assuming perturbed chains [49]), or on reference correlations and empirical fitting [29,44].

This study is conducted based on the average composition of the natural gas from the Danish grid in 2014 after removal of carbon dioxide and heavy hydrocarbons, which gives an approximate composition of $90.30 \%$ methane, $6.02 \%$ ethane, $2.43 \%$ propane, $0.37 \% i$-butane, $0.57 \% n$-butane and $0.31 \%$ nitrogen on a molar basis.

\subsection{Thermodynamic models}

Thermodynamic models aim to predict the thermophysical properties of a given substance, as well as the phase equilibra of a specific mixture. They are used in computer-aided tools to design adequately separation processes and chemical systems. They have various ranges of application (temperature, pressure, chemical components), although they may be extrapolated at the expense of higher inaccuracies. The most wellknown thermodynamic models are the equations of state. They have, at first, been formulated under the form $p(v, T)$, where $p$ is the absolute pressure, $v$ the molar volume and $T$ the temperature. They may as well be given as a function of the compressibility factor $Z(v, T)$ :

$$
Z \equiv \frac{p v}{R T}
$$

\subsubsection{Cubic equations of state}

Classical models for hydrocarbon mixtures are cubic equations of state, because they are applicable over large ranges of temperature and pressure, are generally consistent around the critical point, and are computationally-efficient. The term cubic means that the volume term is of the 1st, 2nd or 3rd order (Table A.4). The $p(v, T)$ relation can be formulated, following the approach of Michelsen and Mollerup[50], as:

$$
p=\frac{R T}{v-b}-\frac{a(T)}{\left(v+\delta_{1} b+\delta_{3} c\right)\left(v+\delta_{2} b+\delta_{4} c\right)}
$$

where $R$ is the ideal gas constant, equal to $8.314472 \mathrm{~J} \cdot \mathrm{mol}^{-1} \cdot \mathrm{K}^{-1} ; a$ is an attraction-related parameter, expressed as a function of the temperature; $b$ is a volume-related parameter, expressed as a function of the size of the molecules; $c$ is a volume-translation parameter, suggested by Péneloux et al.[51] to reproduce the molar volume of boiling liquid at normal pressure; $\delta_{1}, \delta_{2}, \delta_{3}$ and $\delta_{4}$ are empirical constants specific to each equation. Cubic equations of state can be applied to mixtures by applying mixing rules to the calculations of the attraction- and volume-related terms, as well as of the critical pressure and temperatures.

The principal models are the Redlich-Kwong [26] with Soave modifications [27] and Peng-Robinson [24] EOS. They differ in the expression of the attraction- and volume-related parameters, and the exact differences are presented in details in Appendix A. The PR-EOS is generally claimed to be more reliable than the SRKEOS for estimation of the liquid densities, but performs worse for the modelling of polar systems, and other methods may be preferred for higher accuracy [44].

Cubic EOS present numerous advantages such as their simplicity and satisfying prediction of the vapourliquid equilibrium over large ranges of temperature and pressure, but present as well several shortcomings. 
Firstly, the calculations of thermophysical properties are not accurate enough over the whole operating range of temperatures and pressures encountered in LNG applications. This is especially the case for methane, where the deviation in density values reaches up to $5 \%$ below $30 \mathrm{MPa}$, compared to the reference EOS of Setzmann and Wagner[52]. Secondly, as suggested in Trebble and Bishnoi[53], cubic EOS have high inaccuracies when predicting phase equilibria of gas mixtures containing polar components such as water and glycol. The original formulation of cubic models is often customized when applid in simulation software to improve the prediction of few thermophysical properties. The modifications considered in this work are the use of the Rackett equation [54] for the prediction of the molar liquid volume in the Peng and Robinson model, and the implementation of a co-volume parameter as in the approach of Péneloux and Rauzy [51] in the Redlich and Kwong equations.

\subsubsection{Virial equations of state}

Equations of state of the virial family have also been of interest for modelling hydrocarbon systems. They find their origin in statistical mechanics, based on the knowledge of quantities on molecular level, and they are expressed as a power series of the molar volume:

$$
p=\frac{R T}{v}\left(1+\frac{B(T)}{v}+\frac{C(T)}{v^{2}}+\ldots\right)
$$

where the slope parameters are called the virial coefficients, $B(T)$ being the second virial coefficient, $C(T)$ the third one, etc. They account for interaction potential between particles and therefore for deviations from the ideal gas law, and they are only dependent on temperatures for pure components. These parameters are usually derived empirically for a selected number of chemical components, and the first main equation of the virial family that is applied to gas modelling is the Benedict-Webb-Rubin [31,32] with Starling adjustments [48].

It led to the development of supposedly more accurate models that include a higher number of fitting parameters, such as the Lee-Kesler (LK) equation of state [33]. The latter was adapted further to mixtures by Plöcker et al.[34] into the so-called Lee-Kesler-Plöcker (LKP) model. Compared to the conventional cubic equations of state, the LKP-EOS may be more accurate for the prediction of liquid volumes of some hydrocarbon mixtures. The exact differences between both models are presented in details in Appendix B. Virial equations may be used for mixtures: specific mixing rules apply to the calculations of the virial and empirical factors for the BWRS EOS, while they are apply to the derivations of the critical properties and compressibility factor for the LKP EOS.

In general, virial equations are usually accurate for predicting the enthalpy and entropy of hydrocarbons [55]. However, they are applicable for a more limited range of temperatures and pressures, and are more suited for gases with light components.

\subsubsection{Molecular-based equations of state}

Cubic equations of state build on the hypothesis that molecules are spherical and do not associate, which makes them unsuitable for predicting the phase equilibria of mixtures with site-site effects such as hydrogen bonding. Other equations of state are based on a more detailed study of molecular interactions, such as associative effects, although their level of complexity is higher. They consider the effects of hydrogen bonding between like- (self-association) and unlike- (cross-association) molecules and the corresponding models are divided in three categories: lattice, chemical and perturbation [56].

Perturbation theories build on statistical mechanics for deriving molecular models and for calculating the total energy of hydrogen bonding. They are based on the formalism of Wertheim[57,58,59] where systems are modelled as a repulsive core and multiple interaction sites that enable the formation of chains and closed rings. In other words, molecular interactions can be divided into a repulsive part, which is calculated by taking a reference fluid in which no attractions are present, and a contribution due to attraction effects, which are considered as a perturbation to that reference.

The 'Statistical Association Fluid Theory' (SAFT) $[35,36]$ builds on the following considerations. A molecule (i) contains chain and association sites, (ii) is represented as equal-sized hard spheres, (iii) is 
subject to attractive forces with other molecules (dispersive potential such as Lennard-Jones), (iv) presents chain sites, which enable the formation of chain molecules, (v) displays association sites, which enable the formation of association complexes by hydrogen bonding. SAFT equations build on derivations from the residual Helmholtz free energy $a^{r}$, which is expressed in a reduced form $\alpha^{r}$ as:

$$
\alpha^{r} \equiv \frac{a^{r}(T, \rho)}{R T}=\alpha^{\text {seg }}+\alpha^{\text {chain }}+\alpha^{\text {assoc }}
$$

where $\alpha^{\text {seg }}$ is the free Helmholtz energy of the segment, consisting of the hard-sphere reference and dispersion terms, which represents segment-segment interactions, $\alpha^{\text {chain }}$ the contribution from chain formation and $\alpha^{\text {assoc }}$ the contribution from association effects. These terms are dependent of three molecule characteristics: the number of segments $m$, the temperature-independent segment diameter $\sigma$, which is related to the molecule size, and the depth of pair potential $\varepsilon$, which is related to the segment energy, parameters. Two additional parameters are considered if the component is self-associating: the volume $\varepsilon^{\mathrm{AB}}$ and energy $\kappa^{\mathrm{AB}}$ of association.

The most widely used SAFT equation of state for hydrocarbon modelling is called PC-SAFT [49,60], where PC stands for 'Perturbated Chain'. At the difference of other SAFT variants, molecules are seen as chains of jointed spherical segments with association sites and polar groups. The reference fluid is taken as a hard-sphere chain to which the perturbation theory of Barker and Henderson[61,62] is applied. For non-associating components [60], the residual Helmholtz free energy consists of the hard-chain reference contribution $a^{\text {hc }}$ to which a chain dispersion term $a^{\text {disp }}$ is added:

$$
\alpha^{r}=\alpha^{\mathrm{hc}}+\alpha^{\mathrm{disp}}
$$

A more thorough overview of the equations behind the derivation of the PC-SAFT model is presented in details in Appendix C. Few studies compare SAFT and cubic EOS, with sometimes contradictory results, with Diamantonis et al.[43] suggesting that the PC-SAFT equation is generally more accurate, at the opposite of Alfradique and Castier[63].

\subsubsection{Empirical multiparameter equations of state}

Despite these improvements, the development of gas processing systems has resulted in an increasing demand for a high accuracy in the prediction of the properties of natural gas mixtures. Standard equations of state may present too high inaccuracies (e.g. greater than $1 \%$ for the prediction of enthalpy differences) and may not be applicable for all types of mixtures encountered in gas processing. Empirical multiparameter equations of state have been developed with the purpose of addressing these shortcomings. Examples of such models for pure substances are the reference equations of state. They describe, in a single equation, all experimental thermodynamic property data available, within their experimental uncertainty. They are usually explicit in terms of the Helmholtz free energy $a$, expressed in a reduced form $\alpha$. It includes a first part that describes the behaviour of the hypothetical ideal gas at given values of temperature and density, and with a second part that describes the residual behaviour of the real fluid at the same conditions:

$$
\alpha(T, \rho) \equiv \frac{a(T, \rho)}{R T}=\alpha^{o}(T, \rho)+\alpha^{r}(T, \rho)
$$

where the ideal gas part $\alpha^{o}$ is often based on experimental or spectroscopic data, and the residual part $\alpha^{r}$ is estimated and corrected empirically.

In the case of mixtures, the dimensionless Helmholtz free energy of a mixture is derived based on a multifluid approximation. The models use fundamental equations of state for each mixture component, along with further equations to account for the residual mixture behaviour. The advantage of this approach is the accurate calculation of the pure component contributions to the residual Helmholtz free energy, while the main drawback is the use of the same mixing rule to the whole equation of state.

The ideal gas and residual contributions to the Helmholtz free energy are therefore given as a function of the vector of molar fractions $\bar{x}$ besides the temperature and density:

$$
\alpha(T, \rho, \bar{x}) \equiv \frac{a(T, \rho, \bar{x})}{R T}=\alpha^{o}(T, \rho, \bar{x})+\alpha^{r}(T, \rho, \bar{x})
$$


It is more conveniently reformulated with the inverse reduced temperature and reduced density of the complete mixture, as is particularly advantageous if the critical temperatures and densities of the mixture components are significantly different. The reduced Helmholtz free energy is then formulated as:

$$
\alpha(\tau, \delta, \bar{x}) \equiv \frac{a(T, \rho, \bar{x})}{R T}=\alpha^{o}(\tau, \delta, \bar{x})+\alpha^{r}(\tau, \delta, \bar{x})
$$

where $\tau$ and $\delta$ are defined as:

$$
\tau \equiv \frac{T_{r}}{T} \text { and } \delta \equiv \frac{\rho}{\rho_{r}}
$$

with $T_{r}$ and $\rho_{r}$ are the composition-dependent reducing functions for the mixture temperature and density, given by:

$$
\rho_{r} \equiv \rho_{r}(\bar{x}) \text { and } T_{r} \equiv T_{r}(\bar{x})
$$

At present, the most accurate model for natural gas components was developed by the Groupe Européen de Recherches Gazières (GERG). It covers 18 components (methane, ethane, propane, $n$-alkanes with a carbon number up to $7, i$-alkanes with a carbon number of 4 and 5 , hydrogen, oxygen, carbon oxides, helium, hydrogen, nitrogen and argon) in the 2004-version [29], and 21 in the 2008-version [44] (addition of $n$ nonane, $n$-decane and hydrogen sulphide, based on the reference model of Lemmon and Span[64]). It builds on the use of reference equations of state for each component that have been developed in the last decades, which are mentioned in Appendix D. The GERG model is at present the most accurate model for natural gas mixtures, as the predicted values for all thermophysical properties are in the range of experimental uncertainties.

\subsection{Process models}

LNG systems can be grouped into three classifications based on the type of liquefaction process [65]: cascade, mixed-refrigerant and expander-based, although cascade and expander-based processes may use refrigerant mixtures as working fluids. Three processes are evaluated in the present work: (i) the cascade process, with propane, ethylene and methane in three separate cycles; (ii) the single-stage mixed-refrigerant process, without precooling and without phase separators, and (iii) the reverse Brayton cycle, with nitrogen as working fluid.

In a conventional cascade process (Figure 1), the natural gas feed is precooled, liquefied and subcooled using three pure refrigerants: propane, ethylene and methane. Each refrigerant is evaporated at between one to four pressure levels, meaning that the refrigeration effects are provided at three to twelve constant temperature levels in the resulting number of heat exchangers. The temperature approach between the hot and cold streams reaches its minimum at the cold end of each heat exchanger. Cascade systems are mature, simple, and widely used, but a high performance can be achieved only with a high number of heat exchangers, which makes such systems unsuitable for small-scale applications.

In a typical mixed-refrigerant process (Figure 2), the natural gas temperature is decreased using one (single mixed, SMR) to two (dual mixed, DMR) refrigerants, of which at least one is a zeotropic mixture. In practice, when evaporating, the most volatile components (e.g. methane and nitrogen) boil off first and the least volatile ones (e.g. propane and butane) boil off last, and the composition, temperature and pressure of the refrigerant mixture are adjusted to possibly minimise the temperature approach in the heat exchangers. Mixed-refrigerant systems are easily adaptable to different feed conditions and have the potential for reaching a high performance with fewer components. Several configurations are widely used, but they may not be suitable for offshore applications, where flammability and motion issues are of concern.

Finally, an expander-based process builds on a reverse-Brayton cycle (Figure 3), implying that the working fluid (e.g. nitrogen or methane) temperature is decreased by use of one to several turbo-expanders. The working fluid does not change phase, with the exception of some recent systems where a mixture of methane and nitrogen is employed. The thermodynamic efficiency of these cycles is generally lower than of typical cascade and mixed-refrigerant processes. However, these cycles are simple, inherently safe, present a satisfying dynamic behaviour and are adequate for small-scale and offshore applications. At the difference 

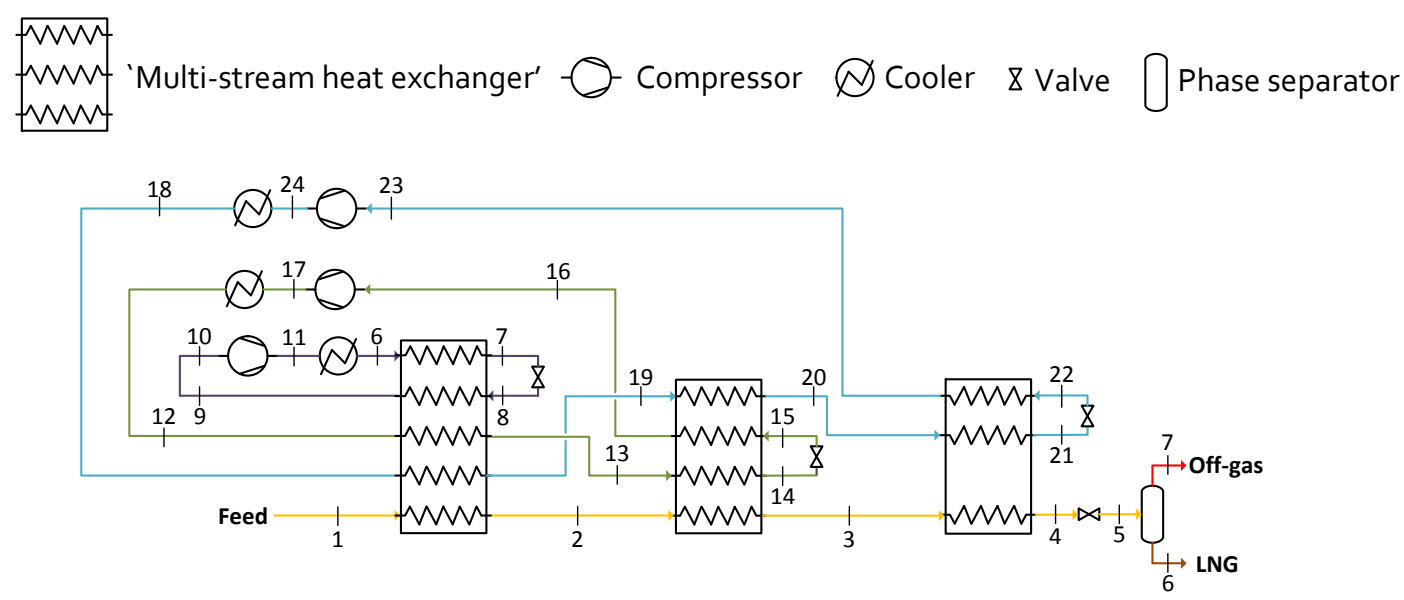

Figure 1: Process flowsheet of the cascade process with pure refrigerants.
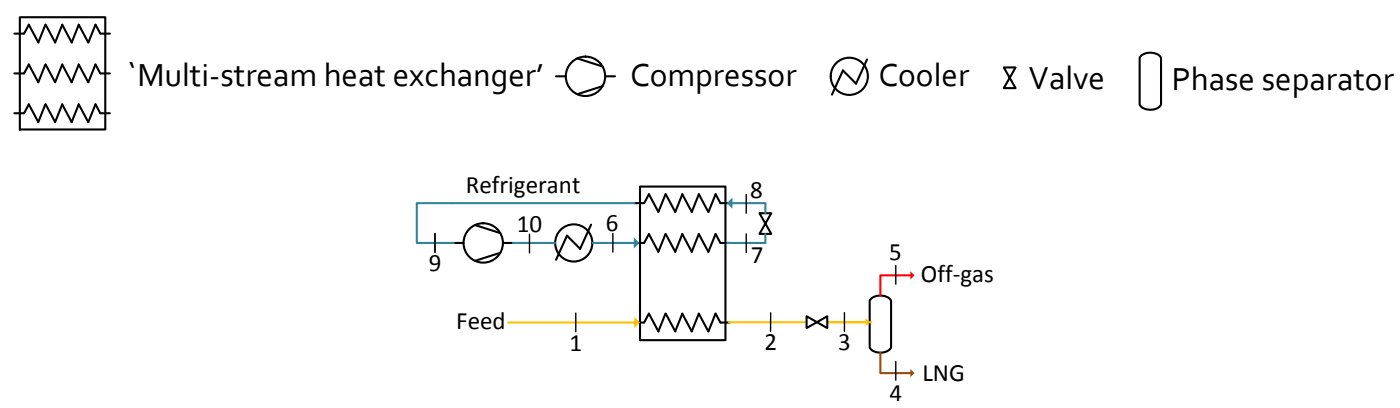

Figure 2: Process flowsheet of the single-stage mixed-refrigerant process.

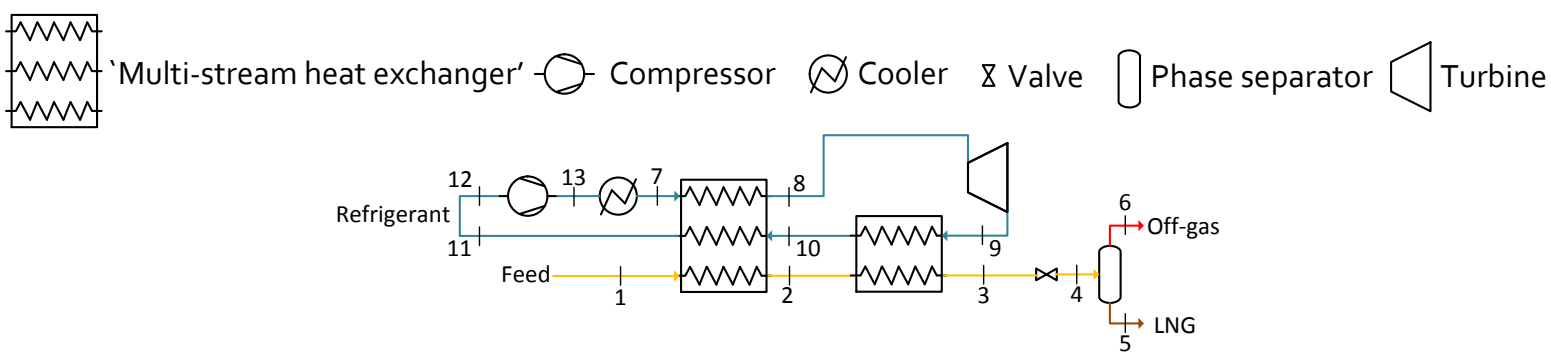

Figure 3: Process flowsheet of the single-stage reverse Brayton process.

of mixed-refrigerant cycles where the cooling effect is generated by throttling effect, expander-based cycles use compression and expansion turbomachines.

The models are developed with Aspen Plus version $7.2[66]$ with the following assumptions. The natural gas feed enters the liquefaction process at a temperature of $20^{\circ} \mathrm{C}$ and a pressure of 32 bar. It is cooled from the ambient temperature to $-162{ }^{\circ} \mathrm{C}$ and is then flashed to atmospheric conditions for storage. As the off-gases from the flash expansion represent less than 0.1 vol- $\%$ of the total feed, they are neither re-liquefied nor used for precooling the feed. The pressure drops in all heat exchangers are zero, heat losses to the 
environment are neglected, the polytropic efficiency of the compressors is set to $72 \%$, and the isentropic efficiency of the turbines is set to $80 \%$.

\subsection{Process evaluation}

Based on the first law of thermodynamics, the energy balance for all liquefaction processes reads as:

$$
\dot{m}_{\mathrm{NG}} \Delta h_{\mathrm{NG}}=\dot{Q}_{\text {cond }}-\dot{W}_{\text {comp }}+\dot{W}_{\text {turb }}
$$

where $\dot{m}_{\mathrm{NG}}$ is the mass flow rate of the natural gas feed, $h$ the specific enthalpy, $\dot{Q}_{\text {cond }}$ the heat rejected to the environment through the condenser(s), $\dot{W}_{\text {comp }}$ the work input to the compressor(s) and $\dot{W}_{\text {turb }}$ the work output from the turbine(s).

Based on the second law of thermodynamics, the entropy balance is expressed as:

$$
\dot{m}_{\mathrm{NG}} \Delta s_{\mathrm{NG}}+\dot{S}_{\text {gen }}=\frac{\dot{Q}_{\text {cond }}}{T_{0}}
$$

where $s$ stands for the specific entropy, $\dot{S}_{\text {gen }}$ the entropy generation rate, which quantifies the deviation of the process from a reversible behaviour, and $T_{0}$ the environmental temperature. The entropy generation is always positive since every system is irreversible in essence. The minimum work required to perform the liquefaction process is deduced from the previous equations and is given by:

$$
\dot{W}_{\mathrm{min}}=\dot{m}_{\mathrm{NG}}\left(\Delta h_{\mathrm{NG}}-\Delta s_{\mathrm{NG}}\right)
$$

The following performance indicators can therefore be defined for gas liquefaction systems:

- the specific power consumption, which expresses the amount of power consumed to produce one unit of liquefied gas;

$$
w_{\mathrm{LNG}} \equiv \frac{\dot{W}}{\dot{m}_{\mathrm{LNG}}}
$$

- the coefficient of performance, which expresses the cooling effect produced for the given power consumption;

$$
\mathrm{COP} \equiv \frac{\left|\dot{Q}_{\mathrm{C}}\right|}{\dot{W}}=\frac{\dot{m}_{\mathrm{NG}}\left|\Delta h_{\mathrm{NG}}\right|}{\dot{W}}
$$

- the figure of merit (FOM), also called second-law efficiency $\varepsilon$, which quantifies the ratio of the minimum work required for liquefaction to the actual work consumed in the process.

$$
\varepsilon \equiv \frac{\dot{W}_{\mathrm{min}}}{\dot{W}}=\frac{\dot{m}_{\mathrm{NG}}\left(\Delta h_{\mathrm{NG}}-T_{0} \Delta s_{\mathrm{NG}}\right)}{\dot{W}}
$$

\subsection{Optimisation problem}

Optimising LNG systems is essential for proposing a design that is technically feasible, with suitable configuration and operating conditions. The main focus is on the evaluation of the impact of different thermodynamic models on the optimisation results. The discrepancies in terms of temperature, heat capacity, and density result in different estimations of the cooling and power demands, and in different predictions of the compressor and heat exchanger sizes. The design parameters, or, in other words, the decision variables in the optimisation problem, correspond to the refrigerant flowrates, pressures and composition. The lower and upper bounds for each decision variable are set based on the available literature and are adapted to the simulations (Table 1 for the cascade process, Table 2 for the mixed-refrigerant process, and Table 3 for the reverse Brayton cycle).

The optimisation problem is defined in relation to the following objectives:

- maximising the system performance (i.e. high figure of merit and small specific power consumption); 
Table 1: Decision variables for the optimisation of the cascade process

\begin{tabular}{lrrr}
\hline Parameter & Variable & Unit & Range \\
\hline Precooling temperature & $T_{2}$ & ${ }^{\circ} \mathrm{C}$ & {$[-40,-25]$} \\
Liquefaction temperature & $T_{3}$ & ${ }^{\circ} \mathrm{C}$ & {$[-100,-90]$} \\
Propane high-pressure & $p_{11}$ & bar & {$[5,35]$} \\
Propane low-pressure & $p_{8}$ & bar & {$[0.5,5]$} \\
Propane flow rate & $\dot{m}_{C_{3} H_{8}}$ & $\mathrm{~kg} / \mathrm{kg}_{\mathrm{NG}}$ & {$[0,240]$} \\
Ethylene high-pressure & $p_{17}$ & bar & {$[10,40]$} \\
Ethylene low-pressure & $p_{15}$ & bar & {$[0.5,2.5]$} \\
Ethylene flow rate & $\dot{m}_{C_{2} H_{4}}$ & $\mathrm{~kg} / \mathrm{kg}_{\mathrm{NG}}$ & {$[0,420]$} \\
Methane high-pressure & $p_{24}$ & bar & {$[15,45]$} \\
Methane low-pressure & $p_{22}$ & bar & {$[0.5,2.5]$} \\
Methane flow rate & $\dot{m}_{C H_{4}}$ & $\mathrm{~kg} / \mathrm{kg}_{\mathrm{NG}}$ & {$[0,660]$} \\
\hline
\end{tabular}

Table 2: Decision variables for the optimisation of the single mixed-refrigerant process

\begin{tabular}{lrrr}
\hline Parameter & Variable & Unit & Range \\
\hline Methane flow rate & $\dot{m}_{C H_{4}}$ & $\mathrm{~kg} / \mathrm{kg}_{N G}$ & {$[0.4,1.1]$} \\
Ethane flow rate & $\dot{m}_{C_{2} H_{6}}$ & $\mathrm{~kg} / \mathrm{kg}_{N G}$ & {$[0.9,2.4]$} \\
Propane flow rate & $\dot{m}_{C_{3} H_{8}}$ & $\mathrm{~kg} / \mathrm{kg}_{N G}$ & {$[0,2.2]$} \\
$n$-butane flow rate & $\dot{m}_{n-C_{4} H_{10}}$ & $\mathrm{~kg} / \mathrm{kg}_{\mathrm{NG}}$ & {$[0,1.2]$} \\
$i$-butane flow rate & $\dot{m}_{i-C_{4} H_{10}} \mathrm{~kg} / \mathrm{kg}_{\mathrm{NG}}$ & {$[0,1.2]$} \\
$n$-pentane flow rate & $\dot{m}_{n-C_{5} H_{12}}$ & $\mathrm{~kg} / \mathrm{kg}_{\mathrm{NG}}$ & {$[0,1.5]$} \\
$i$-pentane flow rate & $\dot{m}_{i-C_{5} H_{12}}$ & $\mathrm{~kg} / \mathrm{kg}_{\mathrm{NG}}$ & {$[0,1.5]$} \\
Nitrogen flow rate & $\dot{m}_{N_{2}}$ & $\mathrm{~kg} / \mathrm{kg}_{\mathrm{NG}}$ & {$[0,1.2]$} \\
High-pressure level & $p_{10}$ & bar & {$[10,40]$} \\
Low-pressure level & $p_{8}$ & bar & {$[1,9]$} \\
\hline
\end{tabular}

Table 3: Decision variables for the optimisation of the reverse Brayton cycle

\begin{tabular}{lrrr}
\hline Parameter & Variable & Unit & Range \\
\hline Nitrogen flow rate & $\dot{m}_{N_{2}}$ & $\mathrm{~kg} / \mathrm{kg}_{\mathrm{NG}}$ & {$[4,15]$} \\
High-pressure level & $p_{13}$ & bar & {$[60,130]$} \\
Low-pressure level & $p_{9}$ & bar & {$[1,15]$} \\
Precooling temperature & $T_{8}$ & ${ }^{\circ} \mathrm{C}$ & {$[-50,-30]$} \\
\hline
\end{tabular}


- minimising the heat exchanger size (small values of the overall heat transfer - area product $U A$ ).

These objectives are actually conflicting: for example, a smaller gap between the temperature-heat profiles of the heat source and sink gives smaller power consumption, but results in turn in larger heat exchangers [67]. This problem can be addressed by performing two types of optimisations: single-objective optimisations (SOO) on e.g. the minimisation of the power consumption are conducted to make a preliminary comparison of different thermodynamic models, and multi-objective optimisations (MOO) are then performed to assess the trade-offs between objectives that are identified as conflicting, e.g. system performance and heat exchanger size. These trade-offs are then displayed as a Pareto border [68], where any better-off with respect to one objective results in a worse-off in relation to another one.

The optimisation problem is also subject to several practical constraints:

- the minimum temperature difference $(\Delta T)$ allowable between the hot and cold streams along the gas liquefaction path is $3^{\circ} \mathrm{C}$, to avoid too large heat exchangers and ensure that the solution is robust enough against process disturbances;

- a minimum vapour fraction of $93 \%$ is required after expansion in the turbines, based on analogy with steam turbines, to prevent blade erosion caused by liquid formation;

- a minimum vapour fraction of $99 \%$ is required at the inlet of the compressors, to avoid liquid droplets in the compression process;

- the streams exiting each heat exchanger are in thermal equilibrium with the ones present on the same side;

- no sub-atmospheric conditions are considered in the mixed-refrigerant and expansion-based processes to minimise the risks of leakage.

These constraints are highly non-linear and are handled by transforming the problem into an unconstrained one, including penalty functions.

The optimisation results can be analysed by studying the dependencies among the decision variables and optimisation objectives. A possibility is to characterise the relations between two variables $x$ and $y$ by performing a statistical assessment and calculating the correlation coefficients of Pearson $r$ :

$$
r_{x, y}=\frac{\sum_{i=1}^{n}\left(x_{i}-\bar{x}\right)\left(y_{i}-\bar{y}\right)}{\sqrt{\sum_{i=1}^{n}\left(x_{i}-\bar{x}\right)^{2} \sum_{i=1}^{n}\left(y_{i}-\bar{y}\right)^{2}}}
$$

This work considers partial correlation coefficients: they are derived from multivariate regressions by describing the relation between the variables $x$ and $y$, while the influence of all other decision variables $z$ is eliminated.

$$
r_{x, y \cdot z}=\frac{r_{x, y}-r_{x, z} r_{y, z}}{\sqrt{\left(1-r_{x, z}^{2}\right)\left(1-r_{y, z}^{2}\right)}}
$$

These coefficients express the statistical relationship between the decision variable of interest and the objective function in datasets containing $n$ values. A value of 1 means a perfect positive correlation, a value of -1 means a perfect negative one, while a value of 0 means that there is no linear relation.

\section{Results}

\subsection{Natural gas properties}

\subsubsection{Thermophysical properties}

Densities. Cubic EOS are generally considered of poor qualities for predicting liquid densities, especially for saturated ones (Figure 4). For a pressure of 32 bar, which is the considered feed pressure in this work, the 
most inaccurate equation of state of the cubic family is the Soave-Redlich-Kwong model, with a deviation of $\pm(0.2-5) \%$, while it is the Benedict-Webb-Rubin with Starling adjustments equation in the virial category, with a deviation of $\pm(0.003-7) \%$. The calculation of the saturated liquid densities shows similar trends, with a deviation of $\pm(0.3-4) \%$ and $\pm(0.05-1) \%$ for the SRK and BWRS models.

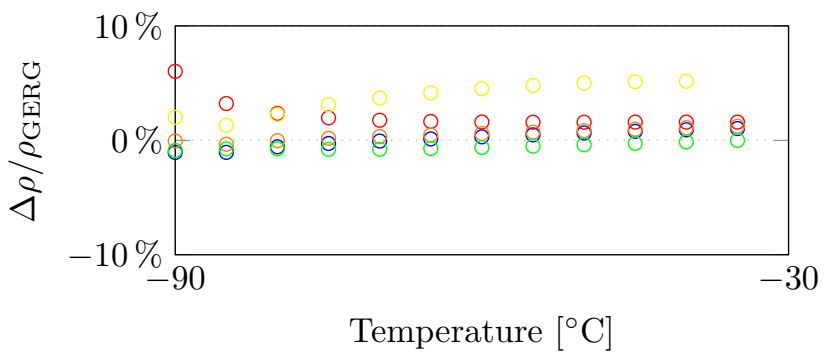

(a) Isobaric liquid densities ( $p=32$ bar)

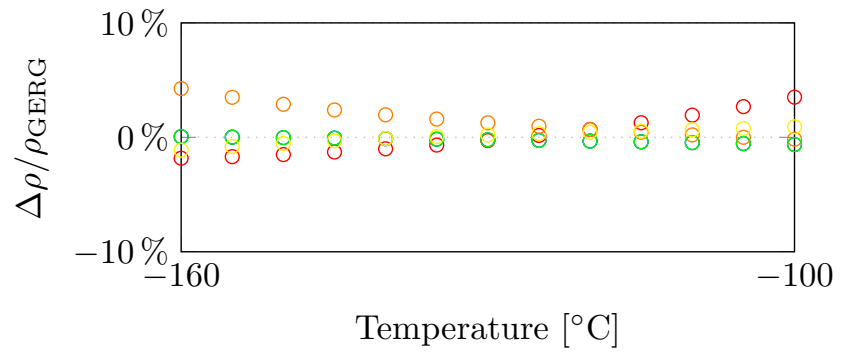

(b) Saturated liquid densities $(x=0)$

\section{$\circ \mathrm{PR} \circ \mathrm{SRK} \circ \mathrm{LKP} \circ \mathrm{BWRS} \circ \mathrm{PC}-\mathrm{SAFT}$}

Figure 4: Percentage deviations of predicted liquid densities $\rho$ for a six-component natural gas, calculated with (i) the cubic equations of state of Peng and Robinson (PR) and of Redlich-Kwong with Soave modifications (SRK), (ii) the virial equations of Lee-Kesler-Plöcker (LKP) and of Benedict-Webb-Rubin with Starling adjustments (BWRS), (iii) the Statistical Associating Fluid Theory with perturbated chain (PC-SAFT), compared to the wide-range multi-parameter model of the Groupe Européen de Recherches Gazières, with the 2008 updates (GERG-2008).

Heat capacities. The computation of the specific heat capacities in isobaric conditions, for the gas phase, shows an excellent agreement for all equations of state (Figure 5), ranging from (0.03-0.4) \% for the BenedictWebb-Rubin-Starling model to (0.1-2) \% for the Peng-Robinson model. However, virial and cubic equations perform poorly for the predictions of caloric properties in liquid conditions, with a deviation of up to 8.3, 13, 8.1 and $8.6 \%$ for the PR, SRK, LKP and BWRS EOS, which suggests that the virial ones are slightly superior. These deviations exceed significantly the experimental uncertainties, which are within $\pm 1-2 \%$, while the results returned by the GERG-2008 model are within $\pm 1 \%$.

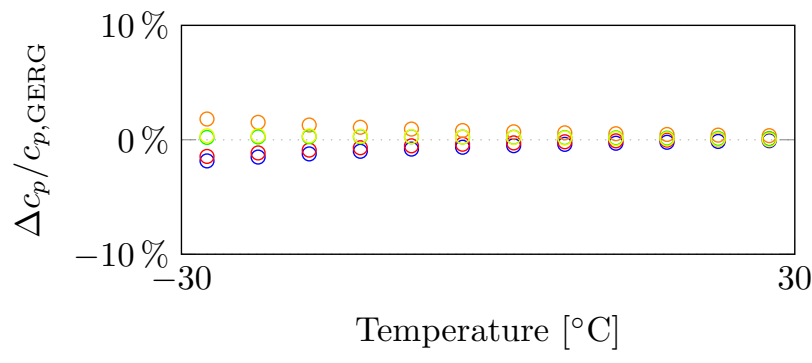

(a) Specific heat capacity (gas)

$$
\circ \mathrm{PR} \circ \mathrm{SRK} \circ \mathrm{LKP}
$$

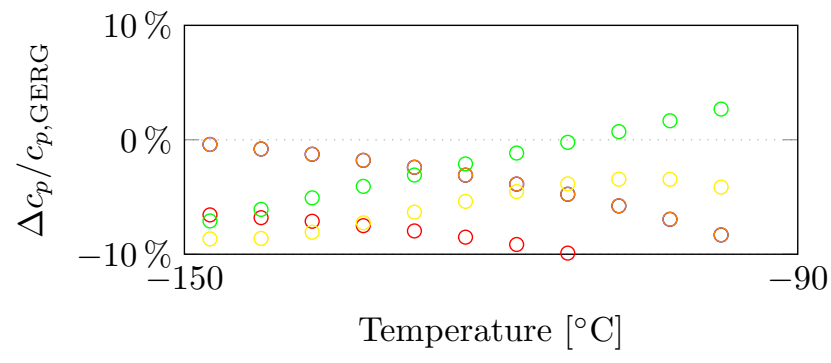

(b) Specific heat capacity (liquid)

BWRS $\circ$ PC-SAFT

Figure 5: Percentage deviations of predicted heat capacities $c_{p}$ for a six-component natural gas, calculated with (i) the cubic equations of state of Peng and Robinson (PR) and of Redlich-Kwong with Soave modifications (SRK), (ii) the virial equations of Lee-Kesler-Plöcker (LKP) and of Benedict-Webb-Rubin with Starling adjustments (BWRS), (iii) the Statistical Associating Fluid Theory with perturbated chain (PC-SAFT), compared to the wide-range multi-parameter model of the Groupe Européen de Recherches Gazières, with the 2008 updates (GERG-2008).

\subsubsection{Vapour-liquid equilibria}

Phase envelope. The accurate description of the phase envelope of the natural gas mixture (Figure 6) is essential for designing any separation process and for designing the heat exchangers. According to Kunz 


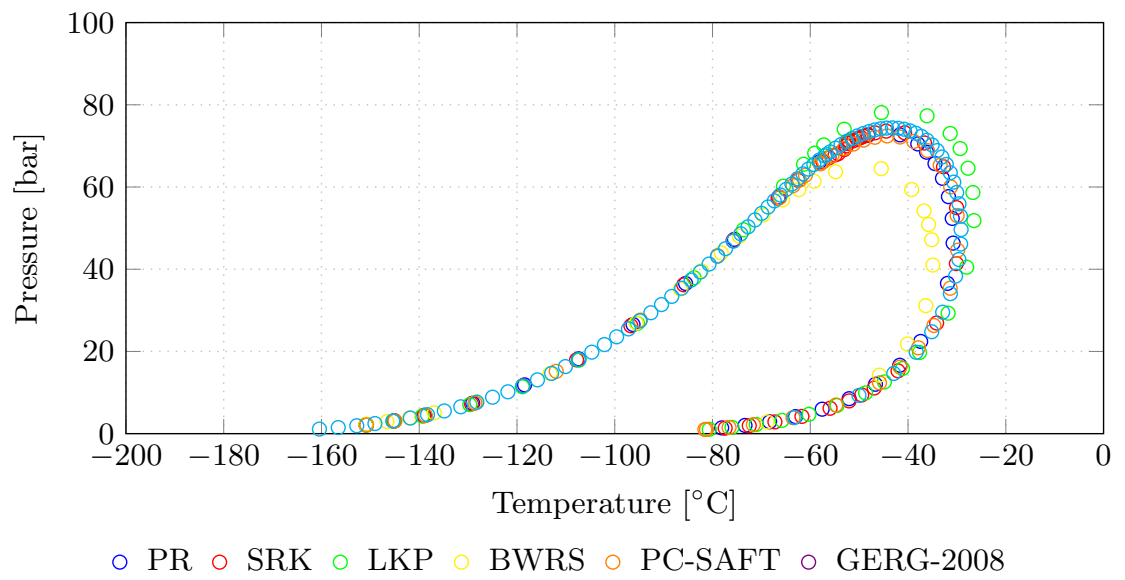

Figure 6: Vapour-liquid phase envelope of a six-component natural gas calculated with (i) the cubic equations of state of Peng and Robinson (PR) and of Redlich-Kwong with Soave modifications (SRK), (ii) the virial equations of Lee-Kesler-Plöcker (LKP) and of Benedict-Webb-Rubin with Starling adjustments (BWRS), (iii) the Statistical Associating Fluid Theory with perturbated chain (PC-SAFT), and (iv) the wide-range multi-parameter model of the Groupe Européen de Recherches Gazières, with the 2008 updates (GERG-2008).

and Wagner[44], experimental measurements of the $p T x y$ relations of natural gas are scarce, but the GERG equations of state predict the bubble- and dew-point pressures within $\pm(1-2) \%$ for the main natural gas components. These uncertainties are within the experimental uncertainty of the measurements for the tested binary mixtures, and all results are compared to those of the GERG-2008 EOS, which is taken as reference.

An excellent agreement between all equations of state, corresponding to a deviation smaller than $0.1^{\circ} \mathrm{C}$, is found for the calculation of the bubble point up to a pressure of 55 bar and for the dew point up to a pressure of 15 bar. On the contrary, significant discrepancies between the virial equations of state and the others are depicted around the critical point. Cubic, 'SAFT' and fundamental EOS are of comparable accuracy, although the PC-SAFT EOS performs slightly better in the prediction of the dew point. A difference of up to $2{ }^{\circ} \mathrm{C}$ is found for a pressure of $32 \mathrm{bar}$, with the largest deviation for the BWRS EOS.

In the case of the vapour fractions, the calculated percentage deviations from the GERG-2008 EOS (Figure 7) are the greatest for cubic EOS and the lowest for the Lee-Kesler-Plöcker model around the bubble point. However, these deviations are significantly lower for cubic EOS above $-80^{\circ} \mathrm{C}$, which deviate

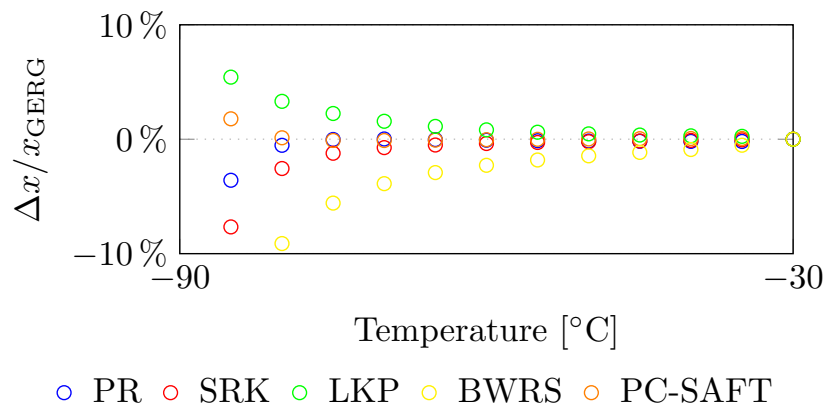

Figure 7: Percentage deviations of predicted molar vapour fraction $x$ for a six-component natural gas, calculated with (i) the cubic equations of state of Peng and Robinson (PR) and of Redlich-Kwong with Soave modifications (SRK), (ii) the virial equations of Lee-Kesler-Plöcker (LKP) and of Benedict-Webb-Rubin with Starling adjustments (BWRS), (iii) the Statistical Associating Fluid Theory with perturbated chain (PC-SAFT), compared to the wide-range multi-parameter model of the Groupe Européen de Recherches Gazières, with the 2008 updates (GERG-2008).

from the reference EOS by $\pm(0.03-0.5) \%$ (Peng-Robinson), while the virial EOS deviate by less than $\pm 1 \%$ 
only over a very limited range of temperatures.

Phase composition. According to Kunz and Wagner[44], the computation of the vapour-phase composition with the GERG EOS returns a difference with experimental results within $\pm(0.005-0.02)$ mole fraction, which is still within the uncertainty range of the measurements. The deviation plots for the six components (Figure 8) present in the studied natural gas show that the smallest deviations are found for light hydrocarbons and nitrogen, whilst the greatest are found for butanes.

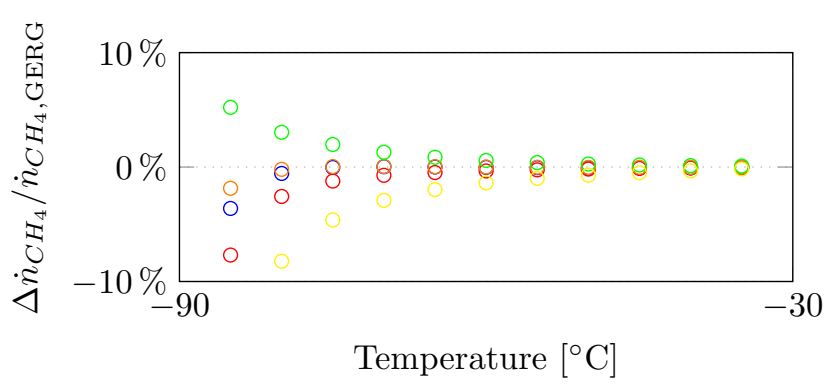

(a) Methane in vapour phase

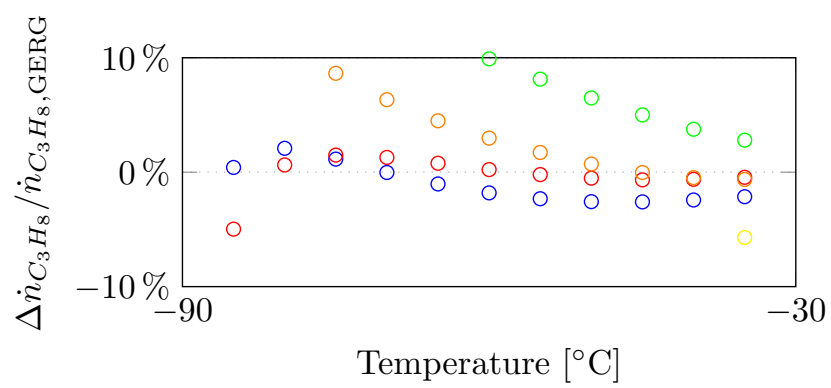

(c) Propane in vapour phase

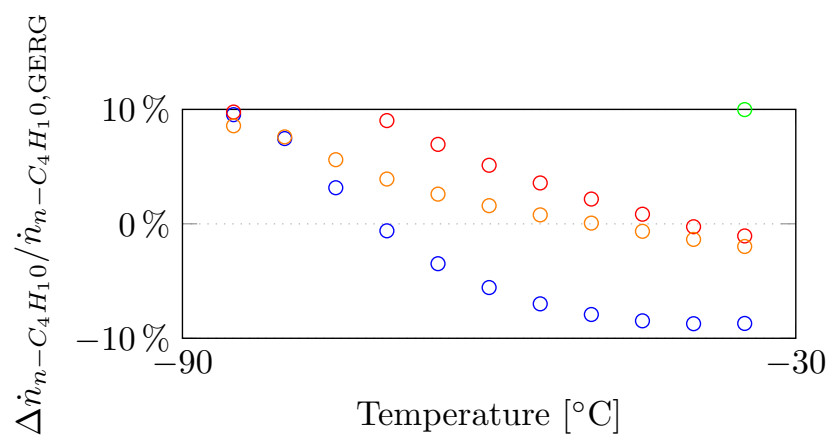

(e) $n$-butane in vapour phase

$$
\circ \mathrm{PR} \circ \mathrm{SRK} \circ \mathrm{LKP}
$$

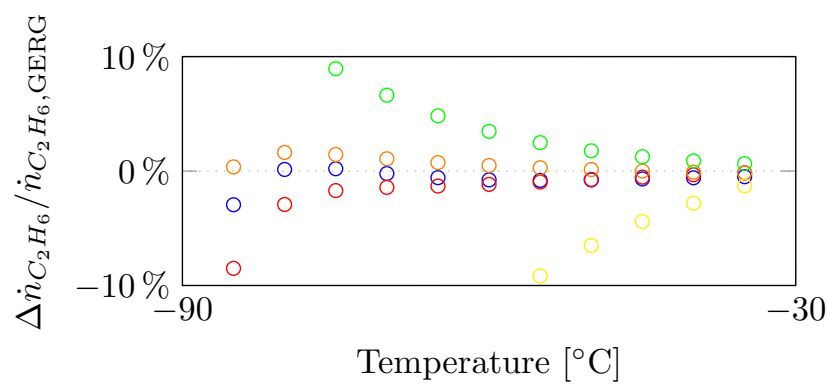

(b) Ethane in vapour phase

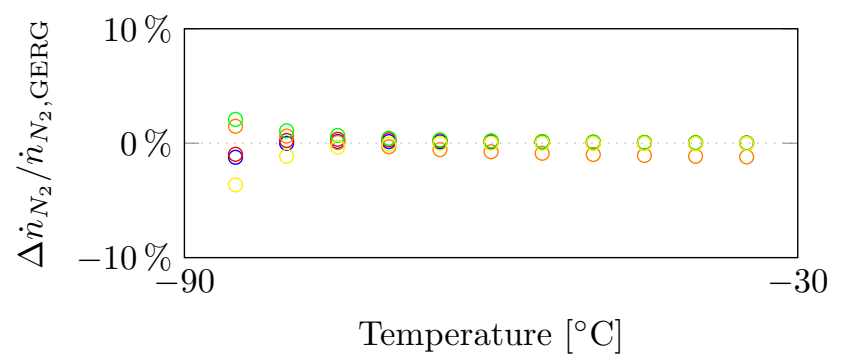

(d) Nitrogen in vapour phase

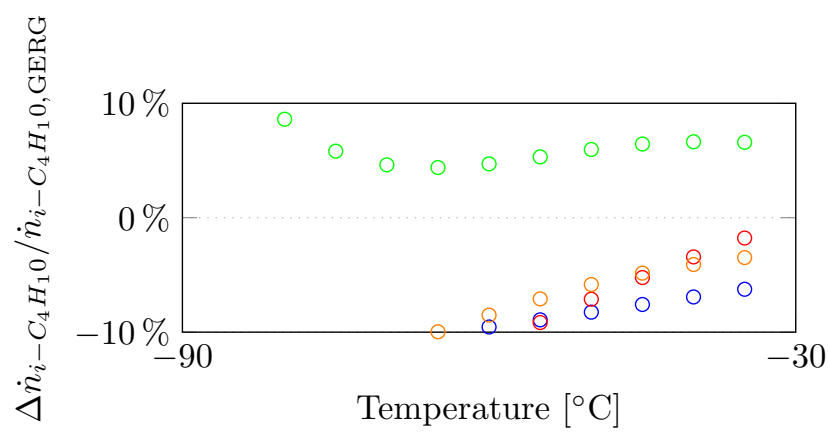

(f) $i$-butane in vapour phase

Figure 8: Percentage deviations of predicted vapour flows of methane $\dot{n}_{C H_{4}}$, ethane $\dot{n}_{C_{2} H_{6}}$, propane $\dot{n}_{C_{3} H_{8}}$ and nitrogen $\dot{n}_{N_{2}}$, for a six-component natural gas, calculated with (i) the cubic equations of state of Peng and Robinson (PR) and of Redlich-Kwong with Soave modifications (SRK), (ii) the virial equations of Lee-Kesler-Plöcker (LKP) and of Benedict-WebbRubin with Starling adjustments (BWRS), (iii) the Statistical Associating Fluid Theory with perturbated chain (PC-SAFT), compared to the wide-range multi-parameter model of the Groupe Européen de Recherches Gazières, with the 2008 updates (GERG-2008).

Deviations are the highest near the bubble point, exceeding $3 \%$ for cubic equations and $5 \%$ for virial ones in the case of methane, and by more than $15 \%$ for $i$-butane. The Benedict-Webb-Rubin-Starling model 
appears to be the most inaccurate one, while the Soave-Redlich-Kwong equation is the least accurate cubic model. These findings confirm the trends observed in the literature, where it is stated that these two EOS are mostly adapted to light hydrocarbons.

\subsection{System simulation}

A baseline case was set up for each process type (cascade, mixed-refrigerant, expander-based) based on a preliminary optimisation of each process, aiming to minimise the net power consumption of the system. They were conducted using the Peng-Robinson equation of state, as this is the most widely used model at present. The results obtained for each model are compared against the GERG multiparameter model, since it presents the smallest uncertainty in terms of thermophysical properties. All simulations were run for a normalised flow of natural gas of $1 \mathrm{~kg} / \mathrm{s}$. As mentioned in Section 1 and in Dauber and Span[45], the GERG model is currently the most accurate one: the prediction of volumetric and calorific properties falls within the range of experimental uncertainties, while the simulations of material and energy flowrates are judged close enough to industrial and applied applications.

\subsubsection{Cascade process}

The baseline case for the cascade process considers three heat exchangers in which the natural gas is liquefied. The pinch points are likely found at the hot or cold end of the heat exchangers, as the refrigerants are pure substances and evaporate therefore at constant temperature levels. The aim is to investigate the differences between each equation of state (Figure 9), in terms of predicted flow rates, heat flows and power consumption, based on the same temperature approach. The baseline case builds on these figures. The high-level pressures are fixed to 8.5 bar for propane $\left(p_{11}\right), 16.7$ bar for ethylene $\left(p_{17}\right)$, and 31.9 bar for methane $\left(p_{24}\right)$. The flow rate and low-pressure level of each refrigerant are calculated to satisfy a minimum temperature approach of $3^{\circ} \mathrm{C}$.

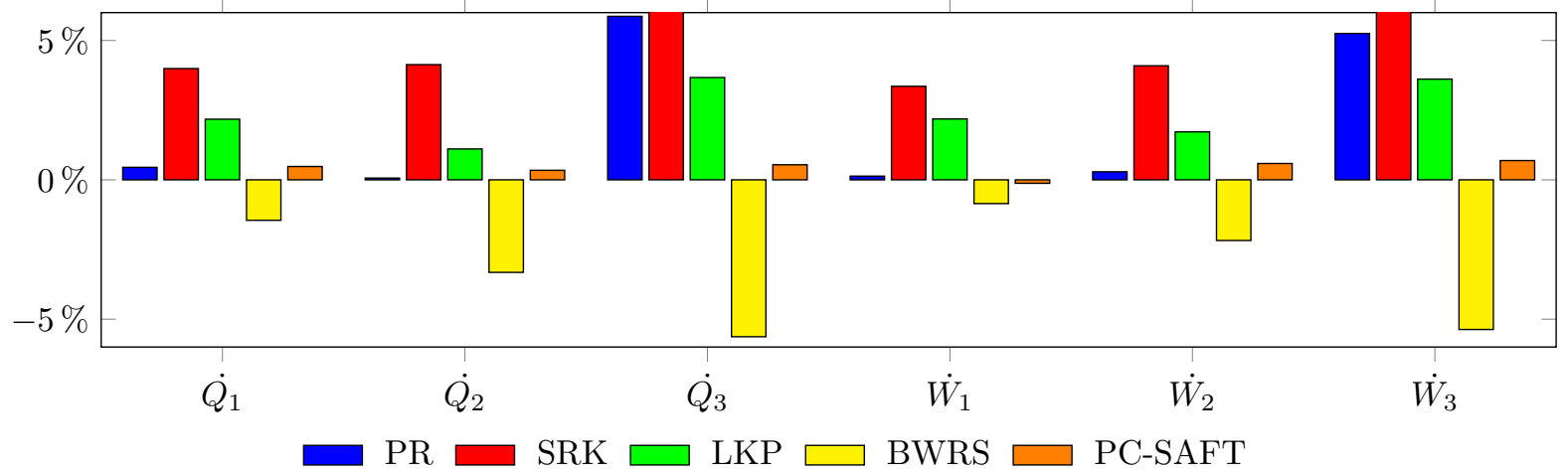

Figure 9: Percentage deviations of predicted heat and power flows for the cascade process, calculated with (i) the cubic equations of state of Peng and Robinson (PR) and of Redlich-Kwong with Soave modifications (SRK), (ii) the virial equations of Lee-Kesler-Plöcker (LKP) and of Benedict-Webb-Rubin with Starling adjustments (BWRS), (iii) the Statistical Associating Fluid Theory with perturbated chain (PC-SAFT), compared to the wide-range multi-parameter model of the Groupe Européen de Recherches Gazières, with the 2008 updates (GERG-2008).

The deviations exceed $\pm 1 \%$ in the case of the Redlich-Kwong equation with Soave adjustments, which is beyond the uncertainty range of the GERG model, claimed to be of $\pm(0.5-1) \%$. These discrepancies are marked for all cubic and virial equations of state, in the cases of the (i) heat exchanged in the third heat exchanger (natural gas subcooling), and (ii) the power consumption of the third refrigeration cycle (methane). The perturbated chain model is satisfactory in all cases. These findings highlight the poor quality of cubic models for deriving the heat capacities of hydrocarbons in liquid state, as well as of virial ones for predicting caloric properties. The SRK-EOS presents marked differences in the calculations of the refrigerant flow rates, as they range from $2.5 \%$ for propane to $11 \%$ for methane. The estimations of the heat exchanger conductances are not satisfactory either, since the deviations reach up to $11 \%$ for the SRK 
model. These inconsistencies are also observed for virial models, although to an extent of only $6 \%$. The PC-SAFT model presents the smallest divergences, which are comprised in the uncertainty range of the GERG model.

\subsubsection{Mixed-refrigerant process}

At the opposite of a conventional cascade system, the pinch point is generally not found at the cold or hot end of each heat exchanger, but within it. The approach used in this comparison is different than the one used for studying the cascade process. The differences between each property model are evaluated (Figure 10), in terms of predicted minimum temperature difference, heat and power flows, based on the same total flow rate of refrigerant. The baseline case for the mixed-refrigerant process is based on the following refrigerant composition, on a molar basis: $29.5 \%$ methane, $33.6 \%$ ethane, $0.4 \%$ propane, $24.7 \%$ butanes, $3.3 \%$ pentanes and $8.5 \%$ nitrogen. The high- $\left(p_{10}\right)$ and low-pressure $\left(p_{8}\right)$ levels are fixed to 25.6 bar and 1.8 bar.

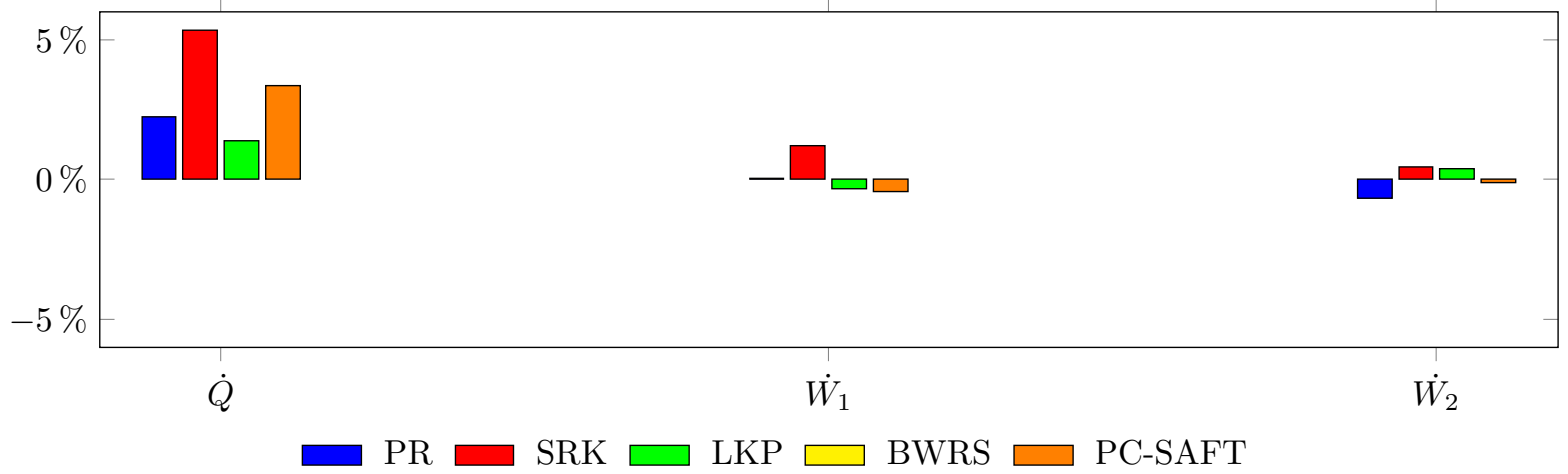

Figure 10: Percentage deviations of predicted heat and power flows for the single mixed-refrigerant process, calculated with (i) the cubic equations of state of Peng and Robinson (PR) and of Redlich-Kwong with Soave modifications (SRK), (ii) the virial equation of Lee-Kesler-Plöcker (LKP), (iii) the Statistical Associating Fluid Theory with perturbated chain (PC-SAFT), compared to the wide-range multi-parameter model of the Groupe Européen de Recherches Gazières, with the 2008 updates (GERG-2008).

The maximum deviations exceed $\pm 5 \%$, in the case of the Redlich-Kwong model with Soave modifications. These deviations exceed the uncertainty range of the GERG model, claimed to be of $\pm(0.5-1) \%$. The virial model of Benedict-Webb-Rubin with Starling adjustments is not applicable in this case, as, in the contrary of all other models, predicts a negative Joule-Thomson coefficient for this mixture, at these conditions. In other words, this model suggests that the refrigerant expansion through the valve results in a higher temperature at the outlet, which is exactly the opposite trend than the one observed in practice. The greatest deviations on the heat exchanged in the liquefaction process are found for cubic equations of state, with a maximum value of $5.3 \%$ for the SRK model. The LKP virial equation presents the smallest deviation, with a value of $1.4 \%$. The predictions of the power consumption are satisfactory in all cases: the discrepancy with the GERG model is below $1 \%$ and is therefore in its uncertainty range. The difference between these models is marked for the heat exchanger conductance and exceeds $5 \%$ in all cases. The expected value is about $450 \mathrm{~kW} / \mathrm{K}$, and the PR, SRK and PC-SAFT models give estimations of 480,500 and $550 \mathrm{~kW} / \mathrm{K}$, meaning that using these models would result into an oversizing of the heat exchangers. Finally, the predictions of the pinch point differ significantly in the SRK and PC-SAFT equations. The GERG model suggests that the point with the minimum temperature difference is located in the heat exchanger, with a difference of $3.3^{\circ} \mathrm{C}$ between the hot and cold streams. The statistical model predicts a pinch point located at the cold end of the heat exchanger, with a difference of $1.9{ }^{\circ} \mathrm{C}$. This discrepancy is related to an inaccurate estimation of the temperature after the Joule-Thomson expansion, which impacts the representation of the temperature-heat profiles. 


\subsubsection{Expander-based process}

Unlike a conventional cascade system, the pinch point is generally not found at the cold or hot end of each heat exchanger, but within it. The approach used in this comparison is different than the one used for studying the cascade process, and similar to the one applied for analysing the mixed-refrigerant process. The differences between each property model are evaluated (Figure 11), in terms of predicted minimum temperature difference, heat and power flows, based on the same total flow rate of refrigerant. The baseline case for the expander-based process builds on the following values: a nitrogen flow rate of $0.258 \mathrm{kmol} / \mathrm{kg}$ of natural gas, a high-pressure level $\left(p_{13}\right)$ of 78.7 bar, a low-pressure level $\left(p_{9}\right)$ of 2.76 bar and a precooling temperature $\left(T_{8}\right)$ of $-42.6{ }^{\circ} \mathrm{C}$.

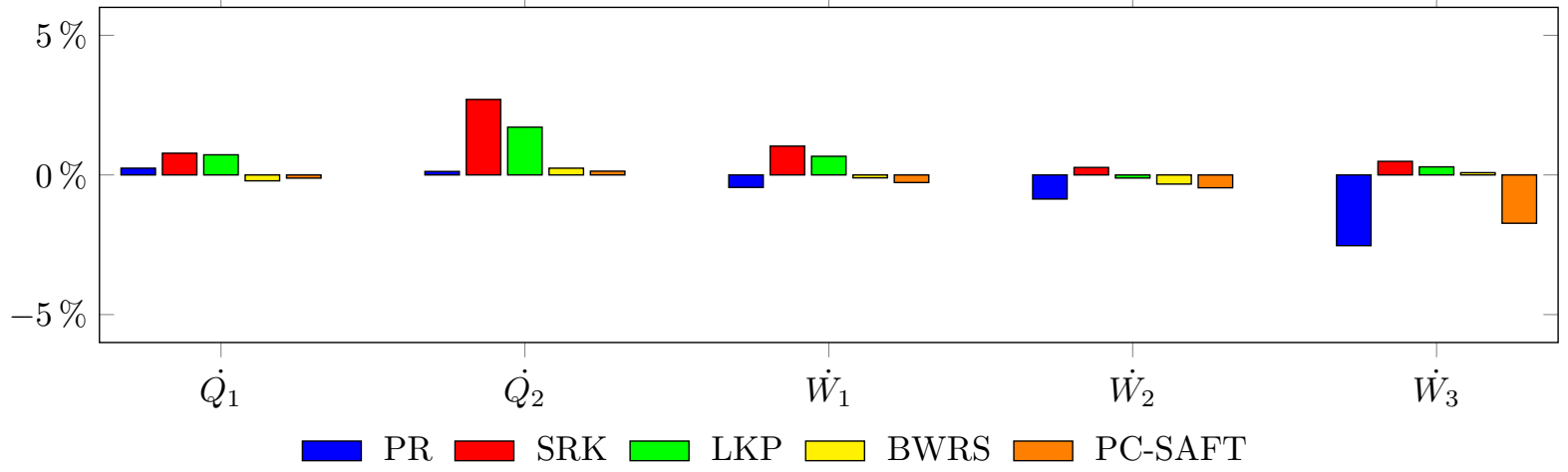

Figure 11: Percentage deviations of predicted heat and power flows for the reverse Brayton cycle, calculated with (i) the cubic equations of state of Peng and Robinson (PR) and of Redlich-Kwong with Soave modifications (SRK), (ii) the virial equations of Lee-Kesler-Plöcker (LKP) and of Benedict-Webb-Rubin with Starling adjustments (BWRS), (iii) the Statistical Associating Fluid Theory with perturbated chain (PC-SAFT), compared to the wide-range multi-parameter model of the Groupe Européen de Recherches Gazières, with the 2008 updates (GERG-2008).

The greatest deviation is found for the cubic equation of Redlich-Kwong with Soave modifications, followed by the virial equation of Lee-Kesler and Plöcker. It corresponds to the heat flow within the second (liquefaction-subcooling) heat exchanger. These deviations are due to the inaccuracies of these models in the description of the vapour-liquid equilibrium and in the derivation of the caloric properties in liquid phase. On the contrary, the deviations observed for the first heat exchanger are less significant. This confirms the previous findings, where it was observed that all equations of state were satisfactory for predicting caloric properties in vapour conditions. The smallest uncertainties for the prediction of the power consumption of each turbomachinery equipment are found for the virial equations, and the highest are found for the Peng and Robinson model. The findings suggest that the perturbated-chain model is actually the most accurate for calculating the plant efficiency.

However, all these models are unsatisfactory when it comes to the calculations of the overall conductances of the heat exchangers. In other words, the temperature-heat profiles for these models are not accurate enough for designing adequately thermal equipments and estimating their heat transfer areas. For the first heat exchanger, the SRK model presents a deviation of about $28 \%$, followed by the LKP model with a discrepancy of about $20 \%$. These figures are smaller for the second heat exchanger, although they exceed $\pm 5 \%$ for all property models. The PC-SAFT model is the least inaccurate one with an overall deviation of about $4 \%$. The prediction of the minimum temperature differences within the heat exchangers is as well not accurate in most cases. The GERG model predicts temperature approaches of about $6.0^{\circ} \mathrm{C}$ and $3.0^{\circ} \mathrm{C}$, while the PR model predicts values of about $6.8^{\circ} \mathrm{C}$ and $4.2^{\circ} \mathrm{C}$.

\subsection{System optimisation}

\subsubsection{Thermodynamic optimisation}

Cascade. The optimal operating conditions for the cascade process correspond to: (i) high-pressure levels of 8-9 bar, 16-19 bar, and 30-32 bar for the propane, ethylene and methane cycles, and (ii) precooling and 
liquefaction temperatures of $-38^{\circ} \mathrm{C}$ and $-100{ }^{\circ} \mathrm{C}$. These findings are similar for the six equations of state investigated in this work. However, the value of the power required in the optimum cascade process differs from one model to another. It ranges from $1550 \mathrm{~kJ} / \mathrm{kg}$ with the equation of Benedict-Webb-Rubin with Starling modifications to $1700 \mathrm{~kJ} / \mathrm{kg}$ with the model of Redlich-Kwong with Soave adjustments, which corresponds to a COP of 0.5 to 0.55 , and a FOM of $28 \%$ to $31 \%$. There exist strong correlations between the net power consumption and the high-pressure levels of the propane and methane cycles, as suggested with the values of the Pearson's and partial coefficients above 0.9 . The interdependencies with other decision variables are less marked, which is illustrated by Pearson's coefficients smaller than \pm 0.2 with all thermodynamic models.

Mixed-refrigerant. The minimum power consumption for the mixed-refrigerant process is approximately $1500 \mathrm{~kJ} / \mathrm{kg}$, and this threshold is similar for all equations of state. This figure is equivalent to a COP of about $56 \%$ and a FOM of $32 \%$. However, an analysis of the process conditions shows differences between the RKS equation on one side, and the PR and PC-SAFT ones on the other side. The first model suggests that there is only one set of optimal conditions: a refrigerant composition of about $24-27 \% \mathrm{CH}_{4}, 34-37 \%$ $\mathrm{C}_{2} \mathrm{H}_{6}, 4-7 \% \mathrm{C}_{3} \mathrm{H}_{8}$ and 11-13\% N $\mathrm{N}_{2}$, a high-pressure level of 27 bar and a low-pressure level of 1.9 bar. On the contrary, the latter models indicate that there are two sets of optimal conditions. The first one corresponds to a refrigerant composition of 22-23\% $\mathrm{CH}_{4}, 37-39 \% \mathrm{C}_{2} \mathrm{H}_{6}, 5-6 \% \mathrm{C}_{3} \mathrm{H}_{8}$ and $11-12 \% \mathrm{~N}_{2}$, for a high-pressure level of $14 \mathrm{bar}$ and a low-pressure level of 1.6 bar. The second one corresponds to a refrigerant composition of $31-32 \% \mathrm{CH}_{4}, 31-32 \% \mathrm{C}_{2} \mathrm{H}_{6}, 7-8 \% \mathrm{C}_{3} \mathrm{H}_{8}$ and $11-12 \% \mathrm{~N}_{2}$, for a high-pressure level of 32 bar and a lowpressure level of 2.9 bar. The statistical analysis pinpoints strong correlations between the propane, $n$-butane, $i$-pentane, nitrogen flow rates and the power consumption, since both the Pearson's and partial correlation coefficients exceed \pm 0.9 . However, the cubic and statistical models are in disagreement with respect to the ethane content. The first models suggest no direct linear correlation with the power consumption, while the latter describe the opposite trend.

Expander-based. The minimum power consumption for the expander-based process is about $3300 \mathrm{~kJ} / \mathrm{kg}$. This limit is identical for all thermodynamic models and is equivalent to a COP of 0.25 and a FOM of $15 \%$. However, significant discrepancies exist between all models in terms of optimal operating conditions. The GERG multiparameter model suggests that the lowest power consumption is achieved for a precooling temperature as low as possible, near $-60^{\circ} \mathrm{C}$, and for a nitrogen flow rate as small as $0.19 \mathrm{kmol} / \mathrm{kg}_{\mathrm{NG}}$. On the contrary, cubic and virial equations suggest that a precooling temperature in the range of -40 to $-30{ }^{\circ} \mathrm{C}$ and a flowrate of about $0.24 \mathrm{kmol} / \mathrm{kg}_{\mathrm{NG}}$ are optimum. The correlation coefficients are smaller than \pm 0.2 for all variables, with the exception of the precooling temperature, which presents a strong negative correlation with the power consumption.

\subsubsection{Multi-objective optimisation}

A multi-objective optimisation was performed to assess the possibilities to minimise the conductance of the heat exchanger network and the total power consumption. The Pareto frontiers (Figure 12) clearly show these trade-off for all processes, and they indicate that the cascade and mixed-refrigerant processes display the highest thermodynamic performance. The expander-based process is characterised by the smallest values of heat exchanger conductances, as a result of larger temperature gaps between the hot and cold streams in the cryogenic heat exchangers.

The comparison of the Pareto frontiers indicates significant discrepancies among thermodynamic models, especially for the cascade process. For example, a total conductance of $300 \mathrm{~kW} / \mathrm{K}$ corresponds to a net power consumption of $1580 \mathrm{~kW}$ in the model of Benedict-Webb-Rubin with Starling modifications, while it is equivalent to a value of $1740 \mathrm{~kW}$ in the model of Redlich-Kwong with Soave adjustments. These findings illustrate how different derivations of the caloric properties and vapour-liquid equilibrium result in inconsistent designs and optimisations of gas liquefaction processes. A system layout suggested with one thermodynamic model may be discarded with another one because of different values of (i) the temperature approach in the heat exchangers, or of (ii) the vapour fraction of the refrigerants at the compressors inlets. Moreover, these results indicate that it is not possible to state whether one model would systematically 


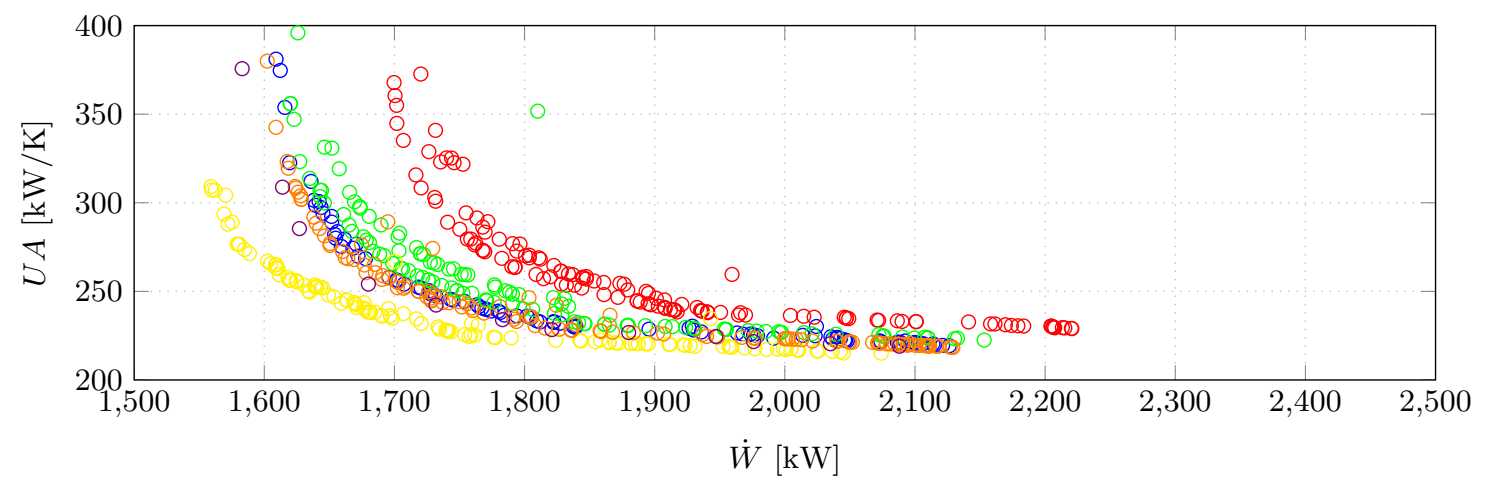

(a) Cascade

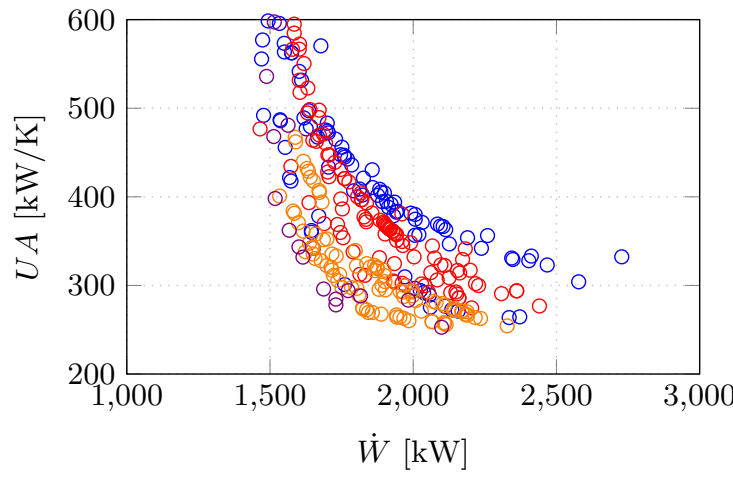

(b) Single mixed-refrigerant

$\circ \mathrm{PR} \circ \mathrm{SRK} \circ \mathrm{LKP}$

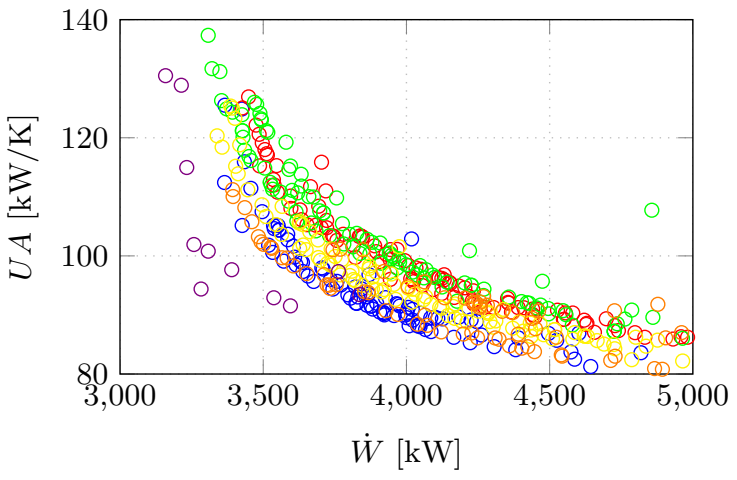

(c) Reverse Brayton cycle

Figure 12: Trade-off between the power consumption and heat network conductance $(U A)$

underestimate the performance of a given process. For example, the SRK model predicts higher power consumption than the PR equation for the cascade and reverse Brayton processes, but lower for the single mixed-refrigerant system.

\subsubsection{System comparison}

Despite the significant differences in terms of power consumption and conductances, the same trends are found for all case studies and equations of state. The single mixed-refrigerant process presents the smallest power consumption, which is associated with the highest heat exchanger conductance, whilst the opposite conclusion is found for the reverse Brayton cycle. The cascade process is characterised by the best compromise between the heat exchanger size and the cycle efficiency. These findings confirm the results presented in the literature, where it is stated that cascade and mixed-refrigerant processes are superior in terms of thermodynamic performance. In addition, they also demonstrate that the cascade process requires less heat exchanger surface area, and thus smaller heat exchangers, because of the wide temperature differences compared to the single mixed-refrigerant process.

\section{Discussion}

\subsection{Prediction of natural gas properties}

Cubic equations of state are still widely used because of their simple structure and the high number of possible customizations, which makes them suitable to various technical applications. However, several 
recent works such as the one of Kunz and Wagner[44] underline their inherent limitations in the description of liquid densities, as the deviation goes up to $15 \%$. The implementation of the volume-translation parameter of Péneloux et al.[51] and of the equation of Rackett[54] in industrial process software has improved markedly the calculations of liquid densities and molar volumes, as the present work suggests. However, the 'volumeshifting' corrections are applicable to a restricted range of the liquid phase and are not sufficient for achieving deviations smaller than experimental uncertainties, as discussed in the work of Kunz and Wagner[44] in the reference cases of Haynes[69].

Virial equations of state were applicable, in their original form, only to the gas phase, but became usable for deriving the properties of liquid phases with further works. As mentioned in Dimian[55], the extended correlations of Benedict-Webb-Rubin and of Lee-Kesler-Plöcker are considered accurate for predicting phase properties. They are still used for the simulation of gas liquefaction processes, as shown in the bibliography of Austbø et al.[23]. However, it is suggested that the results may be unsatisfactory for mixtures, because of the differences in magnitude between the equation parameters of different pure fluids [70]. The present work indicates that virial equations of state may be less accurate than cubic ones for predicting caloric properties and densities. It is confirmed by the research of Nasrifar and Bolland[71], as higher deviations are found for the equation of Benedict-Webb-Rubin than those of Peng and Robinson, for isobaric heat capacities. Similar findings are drawn in the work of Yuan et al.[47], who do not recommend the use of the correlation of Lee-Kesler and Plöcker for predicting vapour-liquid equilibrium.

Statistical models based on the perturbated chain theory have not been widely compared to cubic equations of state for hydrocarbon mixtures. The present work suggests that the calculation of saturated liquid densities seems less accurate, while the prediction of the vapour-liquid equilibrium and caloric properties is more in line with the multiparameter GERG model. These findings are in agreement with the study of Diamantonis et al.[43], where the authors claim that the PC-SAFT model is more accurate than cubic ones if no binary parameters are implemented. However, in general, all these models return unsatisfactory results with regards to the demand for high accuracy of the new hydrocarbon models.

\subsection{Simulation and optimisation of natural gas processes}

These model inconsistencies when predicting natural gas properties impact significantly the simulation and optimisation of gas liquefaction processes. The poor representation of the caloric properties results in large deviations of the predicted heat flows, which are far above the $\pm 0.5-1 \%$ of experimental uncertainties. The greatest discrepancies are found for heat exchangers where subcooling of natural gas takes place, because of the inaccurate calculations of the isobaric heat capacities of liquid hydrocarbons. The work of Dauber and Span[45] also highlights these high uncertainties for the models of Peng and Robinson, Lee-Kesler and Plöcker, and Redlich-Kwong and Soave compared to actual practical data, taken from the Snøhvit liquefaction plant and the Tuscany regasification terminal. These correlation inaccuracies also affect the derivation of optimal operating conditions, which is problematic when designing a complete liquefaction process. The present work shows that different models may lead to large differences in the prediction of the minimum temperature difference within a heat exchanger, and of the power consumption of a refrigerant cycle.

\subsection{Practical implications}

Liquefied natural gas is at present the main alternative to conventional supplies of gas through pipelines, and major new suppliers currently emerge, reshaping local and global gas markets. In the whole LNG chain, from the extraction of gas to its end-use, the natural gas liquefaction is the most costly process with significant investment and operating costs. The former is associated with the sizes of the heat exchangers and compressors, which are assessed in this work by the heat exchanger conductance $U A$ and power consumption $\dot{W}$. The latter is related to the efficiency of the gas liquefaction process, as lower efficiency results in greater fuel costs.

Accurate modelling of the complete system, from the temperature profiles within the cryogenic heat exchanger to the overall power consumption, is essential in real-case applications. As emphasised by Dauber and Span[45], these discrepancies between thermodynamic models should not be disregarded. They can 
cause inappropriate component designs, and ultimately economic losses, since small improvements in terms of power consumption, as calculated in this work, can affect significantly the thermodynamic and economic performance of the LNG system.

A main issue is that these deviations are not systematic: no generic conclusion can be drawn whether using a given model would always result into an over- or downsizing of the heat exchangers and compressors. However, as shown with the statistical assessments, the six thermodynamic models depict the same relationships between the changes in operating conditions and the subsequent variations of the system efficiency. Cubic, virial and perturbated-chain models may therefore be used to compare qualitatively gas liquefaction systems and suggest possible improvements, but may not be used for designing components and predicting the performance of gas liquefaction processes if high accuracy is desired.

\section{Conclusion}

The design of gas liquefaction facilities requires an ad-hoc evaluation of their performance based on the selection of a thermodynamic property model. The GERG-2008 model is currently the most accurate one: it represents all the thermophysical properties of natural gas mixtures under the range of experimental uncertainties. However, equations of state of the cubic, virial and 'molecular-based' families are well-known and have been used widely in the oil and gas industry, as well as in the academia. The present work compares these models systematically in three steps, by applying them to the (i) calculation of natural gas properties, (ii) design and (iii) optimisation of three liquefaction plants (cascade, mixed-refrigerant and expander-based). Large deviations are observed for the prediction of the vapour-liquid equilibrium, liquid densities and heat capacities of the natural gas mixtures. These discrepancies have a significant impact on the simulation of liquefaction processes in terms of predicted energy flows and temperature approaches. These inconsistencies may mislead process engineers and decision-makers when building and evaluating these cryogenic systems. The present research supports therefore the recent works in the field of natural gas modelling, which state that cubic, virial, and molecular-based equations of state are not accurate enough. Future work in the field of gas liquefaction optimisation should preferably build on the use of the GERG model, despite its higher mathematical complexity and greater computational requirements.

\section{Acknowledgements}

This work is part of the Danish societal partnership Blue INNOship and is partly funded by the Innovation Fund Denmark under File No.155-2014-10 and the Danish Maritime Fund. 


\section{Appendix A. Cubic equations of state}

The principal models used in the oil and gas industry and academia are the Peng and Robinson [24] and Redlich-Kwong with Soave modifications [26] equations of state. They differ in the derivation of the attraction- and volume-related parameters (Table A.4).

Table A.4: Parameters in cubic equations of state.

\begin{tabular}{lllll}
\hline & Attraction-related & Volume-related & $\delta_{1}$ & $\delta_{2}$ \\
\hline VDW & $a$ & $b$ & 0 & 0 \\
SRK & ${\frac{a}{T^{\frac{1}{2}}}}^{\frac{1}{2}}$ & $b$ & 1 & 0 \\
PR & $a(T)^{b}$ & $b$ & $1+\sqrt{2}$ & $1-\sqrt{2}$ \\
\hline
\end{tabular}

${ }^{a}$ Inclusion of a temperature-dependent term

${ }^{b}$ General temperature-dependency

They are extended to mixtures by using mixing rules, which build on a one-fluid approach, assuming that the mixture behaves as a pure component. These rules use direct relationships for estimating molecular pair interactions (conformal mixing rules), such as the van der Waals rule, include functions of density or of the excess free energy, such as the rule of Wong and Sandler [72]. For hydrocarbon systems, the most common mixing rules are of the first type, and the attraction- and volume-related parameters are written as follows:

$$
\begin{aligned}
a & =\sum_{i} \sum_{j} x_{i} x_{j} a_{i j}, \quad a_{i j}=\left(1-k_{i j}\right) \sqrt{\left(a_{i i} a_{j j}\right)} \\
b & =\sum x_{i} b_{i}
\end{aligned}
$$

where $k_{i j}$ are binary interaction parameters accounting for mixture non-idealities, which are determined empirically or by correlations.

\section{Appendix B. Virial equations of state}

Virial equations of state include virial parameters, whose values may be adjusted to reproduce experimental data, as illustrated with the equation of Benedict et al.[31,32] (BWR), which has eight empirical parameters $\left(A_{0}, B_{0}, C_{0}, a, b, c, \alpha\right.$ and $\left.\gamma\right)$ :

$p=\frac{R T}{v}+\left(B_{0} R T-A_{0}-\frac{C_{0}}{T^{2}}\right)\left(\frac{1}{v}\right)^{2}+(b R T-a)\left(\frac{1}{v}\right)^{3}+\alpha a\left(\frac{1}{v}\right)^{6}+\frac{c\left(\frac{1}{v}\right)^{3}}{T^{2}}\left(1+\gamma\left(\frac{1}{v}\right)^{2}\right) \exp \left(-\gamma\left(\frac{1}{v}\right)^{2}\right)$

The number of parameters increased (the additional ones being $D_{0}, E_{0}, d$ ) in the work of Starling[48], and the resulting equation of state is named BWRS:

$$
\begin{array}{r}
p=\frac{R T}{v}+\left(B_{0} R T-A_{0}-\frac{C_{0}}{T^{2}}+\frac{D_{0}}{T^{3}}-\frac{E_{0}}{T^{4}}\right)\left(\frac{1}{v}\right)^{2}+\left(b R T-a-\frac{d}{T}\right)\left(\frac{1}{v}\right)^{3}+ \\
\alpha\left(a+\frac{d}{T}\right)\left(\frac{1}{v}\right)^{6}+\frac{c\left(\frac{1}{v}\right)^{3}}{T^{2}}\left(1+\gamma\left(\frac{1}{v}\right)^{2}\right) \exp \left(-\gamma\left(\frac{1}{v}\right)^{2}\right)
\end{array}
$$

For both equations, every parameter must be determined empirically for each single component, which limits its applicability.

More accurate models include the Lee-Kesler (LK) equation of state [33], expanded afterward to mixtures by Plöcker et al.[34] into the so-called Lee-Kesler-Plöcker (LKP) model. The latter model can be expressed 
following the approach of Pitzer[73],Pitzer et al.[74] as a linear function of the acentric factor $\omega$ and of the compressibility factors of a so-called simple (0) fluid (argon, krypton and methane), and a reference $(r$ ) one (n-octane):

$$
Z=Z^{(0)}+\frac{\omega}{\omega^{(r)}}\left(-Z^{(0)}+Z^{(r)}\right)
$$

The compressibility factors for the simple and reference fluids are expressed and derived as a function of the BWR form, as proposed in the work of Lee and Kesler[33]:

$$
Z=1+\frac{B}{V_{r}}+\frac{C}{V_{r}{ }^{2}}+\frac{D}{V_{r}{ }^{5}}+\frac{c_{4}}{T_{r}^{3} V_{r}^{2}}\left(\beta+\frac{\gamma}{V_{r}^{2}}\right) \exp \left(-\frac{\gamma}{V_{r}{ }^{2}}\right)
$$

where the non-empirical terms $p_{r}$ and $T_{r}$ are defined as the reduced pressure and temperature, in relation to the critical properties $p_{c}$ and $T_{c}$, and $V_{r}$ is defined as a function of the fluid volume $V$ :

$$
T_{r}=\frac{T}{T_{c}} \text { and } p_{r}=\frac{p}{p_{c}} \text { and } V_{r}=\frac{p_{c} V}{R T_{c}}
$$

Virial coefficients, when derived for mixtures, become function of temperature and composition. For example, the second virial coefficient $B$, which describes molecular pair interactions, is rigorously derived as [75]:

$$
B(T, \bar{x})=\sum_{i} \sum_{j} x_{i} x_{j} B_{i j}(T)
$$

where the virial coefficient is $B_{i i}$ for a pure component $i$ and $B_{i j}$ for an unlike pair. The pure-component and cross-coefficient parameters are derived by empirical fitting, and the latter is expressed as a function of binary interaction parameters, as in cubic equations of state. The corresponding values for alkanes are given in the works of Tsonopoulos and Heidman[76].

\section{Appendix C. 'SAFT' equations of state}

The equation of state of the 'Statistical Association Fluid Theory' (SAFT) with perturbated chain (PC) builds on a decomposition of the residual Helmholtz free energy into two main contributions, if the fluid is non-associative: the hard-chain reference part and the chain dispersion term. The hard-chain reference contribution is given by:

$$
\alpha^{\mathrm{hc}}=\bar{m} \alpha^{\mathrm{hs}}-\sum_{i} x_{i}\left(m_{i}-1\right) \ln g_{i i}^{\mathrm{hs}}\left(\sigma_{i i}\right)
$$

where $\bar{m}$ is the mean segment number in the mixture:

$$
\bar{m}=\sum_{i} x_{i} m_{i}
$$

The hard-sphere fluid Helmholtz free energy is given on a per-segment basis by the equation of Carnahan and Starling[77]:

$$
\alpha^{\mathrm{hs}}=\frac{1}{\zeta_{0}}\left[\frac{3 \zeta_{1} \zeta_{2}}{\left(1-\zeta_{3}\right)}+\frac{\zeta_{2}^{3}}{\zeta_{3}\left(1-\zeta_{3}\right)^{2}}+\left(\frac{\zeta_{2}^{3}}{\zeta_{3}^{2}}-\zeta_{0}\right) \ln \left(1-\zeta_{3}\right)\right]
$$

where the radial distribution function of the hard-sphere fluid, which indicates the probability density for finding a hard-sphere belonging to the $j$ th molecule at a distance $d$ from a hard sphere belonging to the $i$ th molecule, is deduced from the expressions of Boublík[78] and Mansoori et al.[79]:

$$
g_{i j}^{\mathrm{hs}}=\frac{1}{\left(1-\zeta_{3}\right)}+\left(\frac{d_{i} d_{j}}{d_{i}+d_{j}}\right) \frac{3 \zeta_{2}}{\left(1-\zeta_{3}\right)^{2}}+\left(\frac{d_{i} d_{j}}{d_{i}+d_{j}}\right)^{2} \frac{2 \zeta^{2}}{\left(1-\zeta_{3}\right)^{3}}
$$


where $\zeta_{n}$ is the partial volume fraction defined by:

$$
\zeta_{n}=\frac{\pi}{6} \rho \sum_{i=1}^{N} x_{i} m_{i} d_{i}^{m}, \quad n \in\{0,1,2,3\}
$$

where $d_{i}$ is the temperature-dependent segment diameter given by the equation of Chen and Kreglewski[80]:

$$
d_{i}=\sigma_{i}\left[1-0.12 \exp \left(-3 \frac{\varepsilon_{i}}{k T}\right)\right]
$$

with $\mathrm{N}$ the number of particles.

were $k$ is the Boltzmann constant.

The dispersion contribution is written as a sum of first- and second-order terms following the perturbation theory of Barker and Henderson[61,62]:

$$
\alpha^{\mathrm{disp}}=-2 \pi \rho I_{1}(\eta, \bar{m}) \overline{m^{2} \epsilon \sigma^{3}}-\pi \rho \bar{m} C_{1} I_{2}(\eta, \bar{m}) \overline{m^{2} \epsilon^{2} \sigma^{3}}
$$

where $C_{1}$ is a function of the compressibility and reduced density:

$$
C_{1}=\left(1+\bar{m} \frac{8 \eta-2 \eta^{2}}{(1-\eta)^{4}}+(1-\bar{m}) \frac{20 \eta-27 \eta^{2}+12 \eta^{3}-2 \eta^{4}}{[(1-\eta)(2-\eta)]^{2}}\right)^{-1}
$$

and $\eta$ is the packing fraction:

$$
\eta=\frac{\pi}{6} \frac{N \sigma^{3}}{V}
$$

The terms $\overline{m^{2} \epsilon \sigma^{3}}$ and $\overline{m^{2} \epsilon^{2} \sigma^{3}}$ stand for intermolecular segment-segment interactions between chains:

$$
\begin{aligned}
& \overline{m^{2} \epsilon \sigma^{3}}=\sum_{i} \sum_{j} X_{i} X_{j} m_{i} m_{j}\left(\frac{\epsilon_{i j}}{k T}\right) \sigma_{i j}^{3} \\
& \overline{m^{2} \epsilon \sigma^{3}}=\sum_{i} \sum_{j} X_{i} X_{j} m_{i} m_{j}\left(\frac{\epsilon_{i j}}{k T}\right)^{2} \sigma_{i j}^{3}
\end{aligned}
$$

where the PC-SAFT parameters for pairs of unlike systems $\left(\sigma_{i j}, \epsilon_{i j}\right)$ are derived by conventional combining rules as:

$$
\begin{aligned}
\sigma_{i j} & =\frac{1}{2}\left(\sigma_{i}+\sigma_{j}\right) \\
\epsilon_{i j} & =\sqrt{\epsilon_{i} \epsilon_{j}}\left(1-k_{i j}\right)
\end{aligned}
$$

and the integrals of the perturbation theory are power series in density:

$$
\begin{aligned}
& I_{1}(\eta, \bar{m})=\sum_{i=0}^{6} a_{i}(\bar{m}) \eta^{i} \\
& I_{2}(\eta, \bar{m})=\sum_{i=0}^{6} b_{i}(\bar{m}) \eta^{i}
\end{aligned}
$$

where the coefficients $a_{i}$ and $b_{i}$ depend on the chain length, using the relation proposed by Liu and $\mathrm{Hu}[81]$ :

$$
\begin{aligned}
& a_{i}(\bar{m})=a_{0 i}+\frac{\bar{m}-1}{\bar{m}} a_{1 i}+\frac{\bar{m}-1}{\bar{m}} \frac{\bar{m}-2}{\bar{m}} a_{2 i} \\
& b_{i}(\bar{m})=b_{0 i}+\frac{\bar{m}-1}{\bar{m}} b_{1 i}+\frac{\bar{m}-1}{\bar{m}} \frac{\bar{m}-2}{\bar{m}} b_{2 i}
\end{aligned}
$$

The parameters of the radial distribution function of the hard chain are then adjusted to the pure-component
properties (Table C.5). The PC-SAFT EOS is well-suited to model phase equilibria and calculate bulk
properties of hydrocarbon mixtures, and gives more accurate results with respect to empirical measurements. 
Table C.5: Pure-component parameters of the PC-SAFT equation of state $[49,60]$.

\begin{tabular}{lccccccccc}
\hline & $\mathrm{CH}_{4}$ & $\mathrm{C}_{2} \mathrm{H}_{4}$ & $\mathrm{C}_{2} \mathrm{H}_{6}$ & $\mathrm{C}_{3} \mathrm{H}_{8}$ & $n-\mathrm{C}_{4} \mathrm{H}_{10}$ & $i-\mathrm{C}_{4} \mathrm{H}_{10}$ & $n-\mathrm{C}_{5} \mathrm{H}_{12}$ & $i-\mathrm{C}_{5} \mathrm{H}_{12}$ & $\mathrm{~N}_{2}$ \\
\hline$m$ & 1 & 1.593 & 1.6069 & 2.002 & 2.3316 & 2.2616 & 2.6896 & 2.5620 & 1.2053 \\
$\varepsilon / k(\mathrm{~K})$ & 150.03 & 176.5 & 191.42 & 208.11 & 222.88 & 216.53 & 231.2 & 231.2 & 90.96 \\
$\sigma(\AA)$ & 3.7039 & 3.445 & 3.5206 & 3.6184 & 3.7086 & 3.7584 & 3.7729 & 3.8296 & 3.313 \\
\hline
\end{tabular}

\section{Appendix D. Reference equations of state}

At present, empirical multiparameter equations of state have been developed for reaching a level of accuracy within the uncertainty range of empirical measurements. They are usually explicit in the Helmholtz free energy, most often expressed in a reduced form. It includes two contributions: a part related to an hypothetical ideal gas behaviour, and a residual part associated with the real fluid behaviour. The common form for the reduced Helmholtz energy of the ideal gas can be expressed as:

$$
\alpha^{0}(\tau, \delta)=c_{0} \ln (\tau)+c^{\mathrm{I}} \tau+c^{\mathrm{II}}+\sum_{i=1}^{I_{\mathrm{pol}}} c_{i} \tau^{t_{i}}+\sum_{k=1}^{K_{\mathrm{PE}}} m_{k} \ln \left(1-\exp \left(-\vartheta_{k} \tau\right)\right)+\ln \delta
$$

where the constants $c^{\mathrm{I}}$ and $c^{\mathrm{II}}$ are integration constants related to the definition of the zero states of caloric properties.

The residual contribution can be formulated as a sum of polynomial and exponential terms, where the exponents $c_{k}, d_{k}$ and $t_{k}$ are parameters determined by empirical fitting and structural optimisation:

$$
\alpha^{r}(\tau, \delta)=\sum_{k=1}^{K_{\mathrm{Pol}}} n_{k} \delta^{d_{k}} \tau^{t_{k}}+\sum_{k=K_{\mathrm{Pol}, i}+1}^{K_{\mathrm{Pol}, i}+K_{\mathrm{GERG}, i}} n_{k} \delta^{d_{k}} \tau^{t_{k}} \exp \left(-\delta^{c_{k}}\right)
$$

The recent research in the field of thermodynamic models for LNG applications has been directed towards the development of fundamental equations for methane, ethane, nitrogen and carbon dioxide (Table D.6), since they are the main components of natural gas and usually represent more than $90 \%$ in volume, and afterward in the development of wide-range equations of state for natural gas.

The contribution for the ideal-gas mixture $\alpha^{o}$ is written as a sum of the contributions for the ideal-gas $\alpha_{o i}^{o}$ of each $i$-th component among $N$ substances, with $x_{i}$ the corresponding molar fraction:

$$
\alpha^{o}(\tau, \delta, \bar{x})=\sum_{i=1}^{N} x_{i}\left(\alpha_{o i}^{o}(\tau, \delta)+\ln x_{i}\right)
$$

For the GERG equations of state, the dimensionless form of the reduced Helmholtz free energy $\alpha_{o i}^{o}$ for a given component $i$ in the ideal-gas state is given by:

$\alpha_{o i}^{o}(\tau, \delta)=\ln \delta+\frac{R^{*}}{R}\left[n_{o i, 1}^{o}+n_{o i, 2}^{o} \tau+n_{o i, 2}^{o} \ln \tau+\sum_{k=4,6} n_{o i, k}^{o} \ln \left(\left|\sinh \left(\vartheta_{o i, k}^{o} \tau\right)\right|\right)-\sum_{k=5,7} n_{o i, k}^{o} \ln \left(\cosh \left(\vartheta_{o i, k}^{o} \tau\right)\right)\right]$

where the coefficients $n_{o i, k}$ and $\vartheta$ are determined by empirical fitting and are presented in Kunz and Wagner[44], while $R^{*}$ is the molar gas constant used in the work of Jaeschke and Schley[89], equal to $8.314510 \mathrm{~J} \cdot \mathrm{mol}^{-1} \cdot \mathrm{K}^{-1}$.

Similarly, the residual part $\alpha^{r}$ is written as a function of the residual parts $\alpha_{o i}^{r}$ of each individual substance and of a departure function $\Delta \alpha^{r}$, which accounts for the mixture properties (reduced density, inverse reduced temperature and composition):

$$
\alpha^{r}(\tau, \delta, \bar{x})=\sum_{i=1}^{N} x_{i} \alpha_{o i}^{r}(\tau, \delta)+\Delta \alpha^{r}(\tau, \sigma, \bar{x})
$$


Table D.6: Selected examples of reference equations of state explicit in the Helmholtz free energy for substances usually present in natural gas (light and medium-weight hydrocarbons with impurities). The equations of state marked with the symbol ${ }^{\dagger}$ are the ones used in the wide-range multi-parameter model of the Groupe Européen de Recherches Gazières, with the 2004 and 2008 updates.

\begin{tabular}{|c|c|c|c|c|c|}
\hline \multirow[t]{3}{*}{ Pure substance } & \multirow[t]{3}{*}{ Reference } & \multicolumn{3}{|c|}{ Range of validity } & \multirow[t]{3}{*}{ Number of terms } \\
\hline & & \multicolumn{2}{|c|}{ Temperature (K) } & \multirow{2}{*}{$\begin{array}{c}\text { Pressure }(\mathrm{MPa}) \\
p_{\max }\end{array}$} & \\
\hline & & $T_{\min }$ & $T_{\max }$ & & \\
\hline \multirow[t]{2}{*}{ Methane } & Setzmann and Wagner[52] & 93 & 625 & 1000 & 40 \\
\hline & Klimeck $[82]^{\dagger}$ & 90 & 623 & 300 & 24 \\
\hline \multirow[t]{2}{*}{ Ethane } & Bücker and Wagner[83] & & 673 & 900 & 44 \\
\hline & Klimeck $[82]^{\dagger}$ & 90 & 623 & 300 & 24 \\
\hline \multirow[t]{2}{*}{ Propane } & Span and Wagner $[84]^{\dagger}$ & 85 & 623 & 100 & 12 \\
\hline & Lemmon and Span[64] & & 650 & 1000 & 18 \\
\hline \multirow[t]{2}{*}{$n$-Butane } & Span and Wagner $[84]^{\dagger}$ & 134 & 693 & 70 & 12 \\
\hline & Bücker and Wagner[85] & & 573 & 69 & 25 \\
\hline \multirow[t]{2}{*}{$i$-butane } & Span and Wagner $[84]^{\dagger}$ & 113 & 573 & 35 & 12 \\
\hline & Bücker and Wagner[85] & & 573 & 35 & 25 \\
\hline \multirow[t]{2}{*}{ Water } & Wagner and $\operatorname{Pru} \beta[86]$ & & 1273 & 1000 & 56 \\
\hline & Kunz et al. $[29]^{\dagger}$ & 273 & 1273 & 100 & 16 \\
\hline \multirow[t]{2}{*}{ Nitrogen } & Klimeck $[82]^{\dagger}$ & 63 & 700 & 300 & 24 \\
\hline & Span et al.[87] & & & & 36 \\
\hline \multirow[t]{2}{*}{ Carbon dioxide } & Klimeck $[82]^{\dagger}$ & 216 & 900 & 300 & 22 \\
\hline & Span and Wagner[88] & & 1100 & 800 & 42 \\
\hline
\end{tabular}

The departure function may also be expressed as a function of empirical factors such that the residual part is given by:

$$
\alpha^{r}(\tau, \delta, \bar{x})=\sum_{i=1}^{N} x_{i} \alpha_{o i}^{r}(\tau, \delta)+\sum_{i=1}^{N-1} \sum_{j=i+1}^{N} x_{i} x_{j} F_{i j} \alpha_{i j}^{r}(\delta, \tau)
$$

This function is necessary to improve the accuracy of the mixture model in cases where parameter fitting of the reducing functions is not sufficiently accurate to model the residual mixture behaviour. It was originally developed by [90] for specific mixtures but the formulation was generalised and adapted by [91]. The function $\alpha_{i j, k}^{r}$ depends only on the mixture reduced properties and is given by:

$$
\alpha_{i j, k}^{r}=n_{i j, k} \delta^{d_{i j, k}} \tau^{t_{i j, k}} \exp \left[-\eta_{i j, k}\left(\delta-\varepsilon_{i j, k}\right)^{2}-\beta_{i j, k}\left(\delta \gamma_{i j, k}\right)\right]
$$

where the exponents $d_{i j, k}, t_{i j, k}, \eta_{i j, k}, \beta_{i j, k}$ and $\gamma_{i j, k}$ are derived by empirical fitting and are presented in Kunz and Wagner[44].

The equations of state of the GERG-2008 model are not valid for alkenes but have been expanded for the main ones, such as ethylene and propylene, in the REFPROP program version 9.1 [28].

\section{Nomenclature}

$\begin{array}{ll}A_{0} & \text { Empirical parameter } \\ B & \text { Second virial coefficient } \\ B_{0} & \text { Empirical parameter } \\ C & \text { Third virial coefficient } \\ C_{0} & \text { Empirical parameter } \\ D_{0} & \text { Empirical parameter }\end{array}$

${ }_{611} \quad E_{0} \quad$ Empirical parameter

${ }_{612} \quad K \quad$ Number of terms

${ }_{613} \quad N \quad$ Number of substances

$614 \quad R \quad$ Ideal gas constant, $\mathrm{J} \cdot \mathrm{mol}^{-1} \cdot \mathrm{K}^{-1}$

${ }_{615} R^{*} \quad$ Obsolete ideal gas constant, $\mathrm{J} \cdot \mathrm{mol}^{-1} \cdot \mathrm{K}^{-1}$

${ }_{616} T \quad$ Temperature, $\mathrm{K}$ or ${ }^{\circ} \mathrm{C}$ 


\begin{tabular}{|c|c|c|}
\hline 617 & $T_{c}$ & Critical temperature, $\mathrm{K}$ or ${ }^{\circ} \mathrm{C}$ \\
\hline 618 & $T_{r}$ & Reduced temperature \\
\hline 619 & $V$ & Volume, $\mathrm{m}^{3}$ \\
\hline 620 & $Z$ & Compressibility factor \\
\hline 621 & $\bar{x}$ & Molar composition (vector of molar fractions) \\
\hline 622 & $a$ & Attraction-related parameter \\
\hline 623 & $a$ & Empirical parameter \\
\hline 624 & $a$ & Molar Helmholtz free energy \\
\hline 625 & $b$ & Empirical parameter \\
\hline 626 & $b$ & Volume-related parameter \\
\hline 627 & $c$ & Empirical parameter \\
\hline 628 & $c$ & Volume-translation parameter \\
\hline 629 & $c_{p}$ & Isobaric heat capacity, $\mathrm{J} \cdot \mathrm{mol}^{-1} \cdot \mathrm{K}^{-1}$ \\
\hline 630 & $d$ & Empirical parameter \\
\hline 631 & $i$ & $i^{\text {th }}$ component \\
\hline 632 & $n$ & Empirical parameter \\
\hline 633 & $p$ & Pressure, $\mathrm{Pa}$ \\
\hline 634 & $p_{c}$ & Critical pressure, bar \\
\hline 635 & $p_{r}$ & Reduced pressure \\
\hline 636 & $t$ & Empirical parameter \\
\hline 637 & $x$ & Molar fraction \\
\hline 638 & Abbrevic & ations \\
\hline 639 & BWR & Benedict, Webb and Rubin \\
\hline 640 & BWRS & Benedict, Webb, Rubin and Starling \\
\hline 641 & $\mathrm{COP}$ & Coefficient of Performance \\
\hline 642 & EOS & Equation of State \\
\hline 643 & FOM & Figure of Merit \\
\hline 644 & LK & Lee and Kesler \\
\hline
\end{tabular}

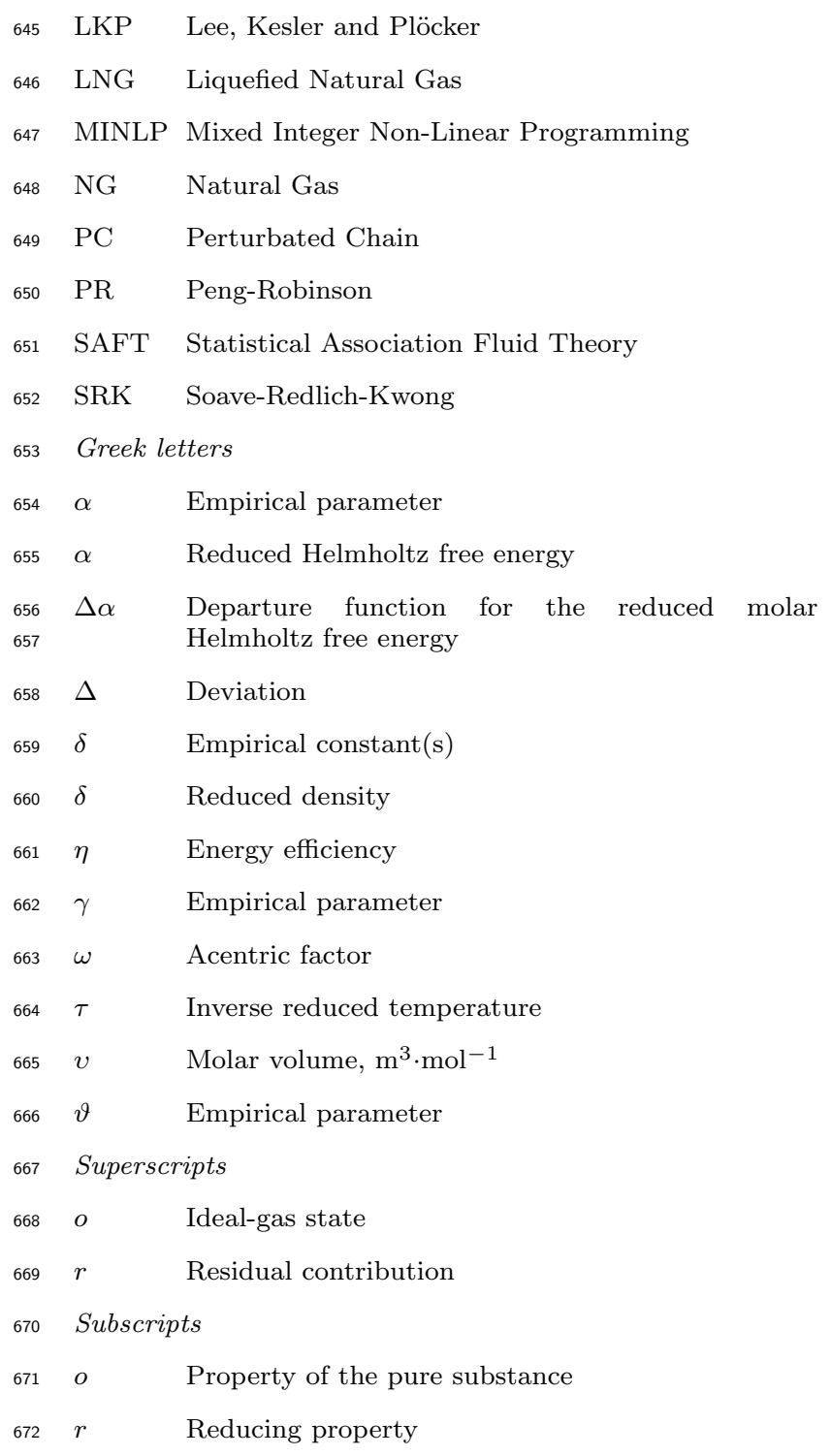




\section{References}

[1] Bosma P, Nagelvoort R. Liquefaction technology; developments through history. In: Proceedings of the 1st annual gas processing symposium; vol. 10. 2009, p. 12.

[2] Habibullah A, Lardi P, Passmore M. LNG conceptual design strategies. In: Proceedings of the 88th GPA Annual Convention. San Antonio, United States; 2009,

[3] Sinor J. Comparison of CNG and LNG technologies for transportation applications. Final subcontract report, June 1991-December 1991. Tech. Rep.; National Renewable Energy Laboratory; Golden, United States; 1992.

[4] International Maritime Organization . Prevention of Air Pollution from Ships. 2016.

[5] McDermott J, Ranney MW. Liquefied natural gas technology. 10; Noyes Publications; 1973.

[6] Mokhatab S, Poe WA. Handbook of natural gas transmission and processing. Gulf Professional Publishing; 2012.

[7] Lim W, Choi K, Moon I. Current status and perspectives of liquefied natural gas (LNG) plant design. Industrial \& Engineering Chemistry Research 2013;52(9):3065-88.

[8] Chang HM. A thermodynamic review of cryogenic refrigeration cycles for liquefaction of natural gas. Cryogenics $2015 ; 72: 127-47$.

[9] Venkatarathnam G, Timmerhaus KD. Cryogenic mixed refrigerant processes. Springer; 2008.

[10] Barclay M, Gongaware D, Dalton K, Skrzypkowski M. Thermodynamic cycle selection for distributed natural gas liquefaction. In: ADVANCES IN CRYOGENIC ENGEINEERING: Transactions of the Cryogenic Engineering Conference-CEC; vol. 710. AIP Publishing; 2004, p. 75-82.

[11] Shukri T. LNG technology selection. Hydrocarbon engineering 2004;9(2):71-6.

[12] Remeljej C, Hoadley A. An exergy analysis of small-scale liquefied natural gas (LNG) liquefaction processes. Energy 2006;31(12):2005-19.

[13] Vink K, Nagelvoort RK. Comparison of baseload liquefaction processes. In: Proceedings 12th International Conference on Liquefied Natural Gas, Paper; vol. 3. 1998,.

[14] Liu L, Daugherty T, Brofenbrenner J. LNG liquefier efficiency. Proceedings of the LNG 1998;12.

[15] Foeg W, Bach W, Stockman R, Heiersted R, Fredheim A. A new LNG base load process and the manufacturing of the main heat exchangers. In: Proceedings of the LNG; vol. 12. 1998, p. 4.

[16] Mortazavi A, Somers C, Hwang Y, Radermacher R, Rodgers P, Al-Hashimi S. Performance enhancement of propane pre-cooled mixed refrigerant LNG plant. Applied Energy 2012;93:125-31.

[17] Li Y, Wang X, Ding Y. An optimal design methodology for large-scale gas liquefaction. Applied Energy 2012;99:484-90.

[18] Khan MS, Lee S, Rangaiah G, Lee M. Knowledge based decision making method for the selection of mixed refrigerant systems for energy efficient lng processes. Applied Energy 2013;111:1018-31.

[19] Xu X, Liu J, Jiang C, Cao L. The correlation between mixed refrigerant composition and ambient conditions in the PRICO LNG process. Applied Energy 2013;102:1127-36.

[20] Cao Ws, Lu Xs, Lin Ws, Gu Az. Parameter comparison of two small-scale natural gas liquefaction processes in skidmounted packages. Applied Thermal Engineering 2006;26(8):898-904.

[21] Lee S, Long NVD, Lee M. Design and optimization of natural gas liquefaction and recovery processes for offshore floating liquefied natural gas plants. Industrial \& Engineering Chemistry Research 2012;51(30):10021-30.

[22] Vatani A, Mehrpooya M, Palizdar A. Energy and exergy analyses of five conventional liquefied natural gas processes. International Journal of Energy Research 2014;38(14):1843-63.

[23] Austb $\varnothing$ B, Løvseth SW, Gundersen T. Annotated bibliography - Use of optimization in LNG process design and operation. Computers \& Chemical Engineering 2014;71:391-414.

[24] Peng DY, Robinson DB. A New Two-Constant Equation of State. Industrial \& Engineering Chemistry Fundamentals $1976 ; 15(1): 59-64$.

[25] Chen CC, Mathias PM. Applied thermodynamics for process modeling. AIChE Journal 2002;48(2):194-200.

[26] Redlich O, Kwong J. ON THE THERMODYNAMICS OF SOLUTIONS. V An Equation of State. Fugacities of Gaseous Solutions. Chemical Reviews 1949;44:233-44.

[27] Soave G. Equilibrium constants from a modified Redlich-Kwong equation of state. Chemical Engineering Science $1972 ; 27(6): 1197-203$.

[28] Lemmon EW, Huber ML, McLinden MO. NIST reference fluid thermodynamic and transport properties - REFPROP. User's Guide Version 9.0; Thermophysical Properties Division, National Institute of Standards and Technology; Boulder, United States; 2002

[29] Kunz O, Klimeck R, Wagner W, Jaeschke M. The GERG-2004 wide-range equation of state for natural gases and other mixtures. VDI Verlag; 2007.

[30] Lemmon E, McLinden M, Huber M. REFPROP: Reference fluid thermodynamic and transport properties. NIST standard reference database $2007 ; 23(8.0)$.

[31] Benedict M, Webb GB, Rubin LC. An Empirical Equation for Thermodynamic Properties of Light Hydrocarbons and Their Mixtures I. Methane, Ethane, Propane and n-Butane. The Journal of Chemical Physics 1940;8(4):334-45.

[32] Benedict M, Webb GB, Rubin LC. An Empirical Equation for Thermodynamic Properties of Light Hydrocarbons and Their Mixtures II. Mixtures of Methane, Ethane, Propane, and n-Butane. The Journal of Chemical Physics 1942;10(12):747-58.

[33] Lee BI, Kesler MG. A generalized thermodynamic correlation based on three-parameter corresponding states. AIChE Journal 1975;21(3):510-27.

[34] Plöcker U, Knapp H, Prausnitz J. Calculation of high-pressure vapor-liquid equilibria from a corresponding-states correlation with emphasis on asymmetric mixtures. Industrial \& Engineering Chemistry Process Design and Development 1978;17(3):324-32. 
35] Chapman WG, Gubbins KE, Jackson G, Radosz M. SAFT: Equation-of-state solution model for associating fluids. Fluid Phase Equilibria 1989;52:31-8.

[36] Chapman WG, Gubbins KE, Jackson G, Radosz M. New reference equation of state for associating liquids. Industrial \& Engineering Chemistry Research 1990;29(8):1709-21.

[37] Ting PD, Joyce PC, Jog PK, Chapman WG, Thies MC. Phase equilibrium modeling of mixtures of long-chain and short-chain alkanes using Peng-Robinson and SAFT. Fluid Phase Equilibria 2003;206(1):267-86.

[38] Martinez SA, Hall KR. Thermodynamic properties of light synthetic natural gas mixtures using the RK-PR cubic equation of state. Industrial \& Engineering Chemistry Research 2006;45(10):3684-92.

[39] Nasrifar K, Bolland O, Moshfeghian M. Predicting natural gas dew points from 15 equations of state. Energy \& fuels $2005 ; 19(2): 561-72$.

40] Aparicio-Martínez S, Hall KR. Use of PC-SAFT for global phase diagrams in binary mixtures relevant to natural gases. 1. n-Alkane+ n-alkane. Industrial \& Engineering Chemistry Research 2007;46(1):273-84.

[41] Aparicio-Martínez S, Hall KR. Use of PC-SAFT for global phase diagrams in binary mixtures relevant to natural gases. 2. n-Alkane+ other hydrocarbons. Industrial \& Engineering Chemistry Research 2007;46(1):285-90.

[42] Aparicio-Martínez S, Hall KR. Use of PC-SAFT for global phase diagrams in binary mixtures relevant to natural gases. 3. Alkane+ non-hydrocarbons. Industrial \& engineering chemistry research 2007;46(1):291-6.

[43] Diamantonis NI, Boulougouris GC, Mansoor E, Tsangaris DM, Economou IG. Evaluation of cubic, SAFT, and PC-SAFT equations of state for the vapor-liquid equilibrium modeling of CO2 mixtures with other gases. Industrial \& Engineering Chemistry Research 2013;52(10):3933-42.

[44] Kunz O, Wagner W. The GERG-2008 wide-range equation of state for natural gases and other mixtures: an expansion of GERG-2004. Journal of chemical \& engineering data 2012;57(11):3032-91.

[45] Dauber F, Span R. Modelling liquefied-natural-gas processes using highly accurate property models. Applied Energy 2012;97:822-7.

[46] Melaaen IS, Owren G. How do the inaccuracies of enthalpy and vapour-liquid equilibrium calculations influence baseload LNG plant design? Computers \& Chemical Engineering 1996;20(1):1-11.

[47] Yuan Z, Cui M, Song R, Xie Y. Evaluation of prediction models for the physical parameters in natural gas liquefaction processes. Journal of Natural Gas Science and Engineering 2015;27:876-86.

[48] Starling KE. Fluid thermodynamic properties for light petroleum systems. Texas, United States: Gulf Publishing Company; 1973.

[49] Gross J, Sadowski G. Application of the perturbed-chain SAFT equation of state to associating systems. Industrial \& engineering chemistry research $2002 ; 41(22): 5510-5$.

[50] Michelsen M, Mollerup J. Thermodynamic models: fundamentals \& computational aspects. Second ed.; Tie-Line; 2007.

[51] Péneloux A, Rauzy E, Fréze R. A consistent correction for Redlich-Kwong-Soave volumes. Fluid Phase Equilibria 1982;8:723.

[52] Setzmann U, Wagner W. A new equation of state and tables of thermodynamic properties for methane covering the range from the melting line to $625 \mathrm{~K}$ at pressures up to $100 \mathrm{MPa}$. Journal of Physical and Chemical Reference Data 1991;20(6):1061-155.

[53] Trebble M, Bishnoi P. Accuracy and consistency comparisons of ten cubic equations of state for polar and non-polar compounds. Fluid Phase Equilibria 1986;29:465-74.

[54] Rackett HG. Equation of state for saturated liquids. Journal of Chemical and Engineering Data 1970;15(4):514-7.

[55] Dimian AC. Integrated Design and Simulation of Chemical Processes. Amsterdam, The Netherlands: Elsevier; 2003.

[56] Kontogeorgis GM, Folas GK. Thermodynamic Models for Industrial Applications: From Classical and Advanced Mixing Rules to Association Theories. ISBN-13 978-0470697269; John Wiley \& Sons; 2009.

[57] Wertheim M. Fluids with highly directional attractive forces. I. Statistical thermodynamics. Journal of statistical physics 1984;35(1-2):19-34.

[58] Wertheim M. Fluids with highly directional attractive forces. II. Thermodynamic perturbation theory and integral equations. Journal of statistical physics 1984;35(1-2):35-47.

[59] Wertheim M. Fluids with highly directional attractive forces. III. Multiple attraction sites. Journal of statistical physics $1986 ; 42(3-4): 459-76$

60] Gross J, Sadowski G. Perturbed-chain SAFT: An equation of state based on a perturbation theory for chain molecules. Industrial \& engineering chemistry research 2001;40(4):1244-60.

[61] Barker JA, Henderson D. Perturbation Theory and Equation of State for Fluids: The Square-Well Potential. The Journal of Chemical Physics 1967;47(8):2856-61.

[62] Barker JA, Henderson D. Perturbation theory and equation of state for fluids. II. A successful theory of liquids. The Journal of Chemical Physics 1967;47(11):4714-21.

[63] Alfradique MF, Castier M. Critical points of hydrocarbon mixtures with the Peng-Robinson, SAFT, and PC-SAFT equations of state. Fluid phase equilibria 2007;257(1):78-101.

[64] Lemmon EW, Span R. Short fundamental equations of state for 20 industrial fluids. Journal of Chemical \& Engineering Data 2006;51(3):785-850.

[65] Bahadori A. Natural Gas Processing: Technology and Engineering Design. Gulf Professional Publishing; 2014.

[66] Aspen Technology . Aspen Plus - Modelling Petroleum Processes. Burlington, USA: Aspen Technology; 1999.

[67] Jensen JB, Skogestad S. Optimal operation of a simple LNG process. In: Proceedings Adchem. 2006, p. 241-7.

[68] Mattson C, Messac A. Pareto Frontier Based Concept Selection under Uncertainty, with Visualization. OPTE: Optimization and Engineering 2005;6(1):85-115.

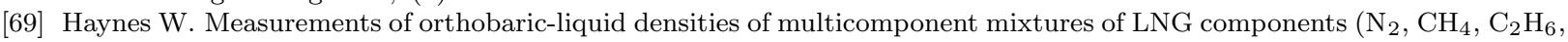


$\mathrm{C}_{3} \mathrm{H}_{8}, \mathrm{CH}_{3} \mathrm{CH}\left(\mathrm{CH}_{3}\right) \mathrm{CH}_{3}, \mathrm{C}_{4} \mathrm{H}_{10}, \mathrm{CH}_{3} \mathrm{CH}\left(\mathrm{CH}_{3}\right) \mathrm{C}_{2} \mathrm{H}_{5}$, and $\left.\mathrm{C}_{5} \mathrm{H}_{12}\right)$ between 110 and $130 \mathrm{~K}$. The Journal of Chemical Thermodynamics 1982;14(7):603-12.

[70] Sengers JV, Kayser R, Peters C, White H. Equations of state for fluids and fluid mixtures. Elsevier; 2000.

[71] Nasrifar K, Bolland O. Prediction of thermodynamic properties of natural gas mixtures using 10 equations of state including a new cubic two-constant equation of state. Journal of Petroleum Science and Engineering 2006;51(3):253-66.

[72] Wong DSH, Sandler SI. A theoretically correct mixing rule for cubic equations of state. AIChE Journal 1992;38(5):671-80.

[73] Pitzer KS. The volumetric and thermodynamic properties of fluids. I. Theoretical basis and virial coefficients. Journal of the American Chemical Society 1955;77(13):3427-33.

[74] Pitzer KS, Lippmann DZ, Curl Jr R, Huggins CM, Petersen DE. The Volumetric and Thermodynamic Properties of Fluids. II. Compressibility Factor, Vapor Pressure and Entropy of Vaporization. Journal of the American Chemical Society 1955;77(13):3433-40.

[75] Poling BE, Prausnitz JM, O'connell JP, et al. The properties of gases and liquids; vol. 5. New York, United States: McGraw-Hill; 2001.

[76] Tsonopoulos C, Heidman J. From the virial to the cubic equation of state. Fluid Phase Equilibria 1990;57(3):261-76.

[77] Carnahan NF, Starling KE. Equation of state for nonattracting rigid spheres. The Journal of Chemical Physics 1969;51(2):635-6.

[78] Boublík T. Hard-Sphere Equation of State. The Journal of Chemical Physics 1970;53(1):471-2.

[79] Mansoori G, Carnahan N, Starling KE, Leland Jr T. Equilibrium thermodynamic properties of the mixture of hard spheres. The Journal of Chemical Physics 1971;54(4):1523-5.

[80] Chen SS, Kreglewski A. Applications of the Augmented van der Waals Theory of Fluids.: I. Pure Fluids. Berichte der Bunsengesellschaft für physikalische Chemie 1977;81(10):1048-52.

[81] Liu H, Hu Y. Molecular thermodynamic theory for polymer systems part ii. equation of state for chain fluids. Fluid Phase Equilibria 1996;122(1):75-97.

[82] Klimeck R. Entwicklung einer Fundamentalgleichung für Erdgase für das Gas-und Flüssigkeitsgebiet sowie das Phasengleichgewicht. Ph.D. thesis; Fakultät für Maschinenbau, Ruhr-Universität Bochum; Bochum, Germany; 2000.

[83] Bücker D, Wagner W. A reference equation of state for the thermodynamic properties of ethane for temperatures from the melting line to $675 \mathrm{~K}$ and pressures up to $900 \mathrm{MPa}$. Journal of physical and chemical reference data 2006;35(1):205-66.

[84] Span R, Wagner W. Equations of state for technical applications. II. Results for nonpolar fluids. International Journal of Thermophysics 2003;24(1):41-109.

[85] Bücker D, Wagner W. Reference equations of state for the thermodynamic properties of fluid phase n-butane and isobutane. Journal of physical and chemical reference data 2006;35(2):929-1019.

[86] Wagner W, Pru $\beta$ A. The IAPWS formulation 1995 for the thermodynamic properties of ordinary water substance for general and scientific use. Journal of Physical and Chemical Reference Data 2002;31(3):387-535.

[87] Span R, Lemmon EW, Jacobsen RT, Wagner W, Yokozeki A. A reference equation of state for the thermodynamic properties of nitrogen for temperatures from 63.151 to $1000 \mathrm{k}$ and pressures to 2200 mpa. Journal of Physical and Chemical Reference Data 2000;29(6):1361-433.

[88] Span R, Wagner W. A new equation of state for carbon dioxide covering the fluid region from the triple-point temperature to $1100 \mathrm{~K}$ at pressures up to $800 \mathrm{MPa}$. Journal of physical and chemical reference data 1996;25(6):1509-96.

[89] Jaeschke M, Schley P. Ideal-gas thermodynamic properties for natural-gas applications. International journal of thermophysics 1995;16(6):1381-92.

[90] Tillner-Roth R. Die thermodynamischen Eigenschaften von R152a, R134a und ihren Gemischen - Messungen und Fundamentalgleichungen. 41; Stuttgart, Germany: Forschungsberichte des Deutschen Kälte-und Klimatechnischer Vereins (DKV); 1993.

[91] Lemmon E. A generalized model for the prediction of the thermodynamic properties of mixtures including vapor-liquid equilibrium. Ph.D. thesis; University of Idaho; Moscow, United States; 1996. 